\title{
Defects of Lipid Synthesis Are Linked to the Age-Dependent Demyelination Caused by Lamin B1 Overexpression
}

\author{
Harshvardhan Rolyan, ${ }^{1}$ Yulia Y. Tyurina, ${ }^{2}$ Marylens Hernandez, ${ }^{3,4}$ Andrew A. Amoscato, ${ }^{2}$ ㄴouis J. Sparvero, ${ }^{2}$ \\ Bruce C. Nmezi, ${ }^{1}$ Yue Lu, ${ }^{5,6}$ Marcos R. H. Estécio, ${ }^{5,6}$ Kevin Lin, ${ }^{5,6}$ Junda Chen, ${ }^{1}$ Rong-Rong He, ${ }^{2}$ Pin Gong, ${ }^{2}$ \\ Lora H. Rigatti, ${ }^{7}$ Jeffrey Dupree, ${ }^{8}$ Hülya Bayır, ${ }^{2,9,10}$ Valerian E. Kagan, $, 211,12,13$ PPatrizia Casaccia, ${ }^{4}$ \\ and Quasar S. Padiath ${ }^{1}$ \\ ${ }^{1}$ Department of Human Genetics, Graduate School of Public Health, University of Pittsburgh, Pittsburgh, Pennsylvania 15216, ${ }^{2}$ Center for Free Radical and \\ Antioxidant Health, Department of Environmental and Occupational Health, Graduate School of Public Health, University of Pittsburgh, Pittsburgh, \\ Pennsylvania 15219, ${ }^{3}$ Friedman Brain Institute Center for Neural Repair, Department of Neuroscience, and ${ }^{4}$ Graduate School of Biological Sciences, The \\ Icahn School of Medicine at Mount Sinai, New York, New York 10029, ${ }^{5}$ Department of Epigenetics and Molecular Carcinogenesis, and ${ }^{6}$ Center for Cancer \\ Epigenetics, The University of Texas MD Anderson Cancer Center, Houston, Texas 77030, ${ }^{7}$ Division of Laboratory Animal Resources, University of \\ Pittsburgh School of Medicine, Pittsburgh, Pennsylvania 15261, ${ }^{8}$ Department of Anatomy and Neurobiology, Virginia Commonwealth University, \\ Richmond, Virginia 23298, and ${ }^{9}$ Safar Center for Resuscitation Research and Departments of ${ }^{10} \mathrm{Critical}$ Care Medicine, ${ }^{11} \mathrm{Pharmacology}$ and Chemical \\ Biology, ${ }^{12}$ Chemistry, and ${ }^{13}$ Radiation Oncology, University of Pittsburgh, Pittsburgh, Pennsylvania 15219
}

Lamin $\mathrm{B} 1$ is a component of the nuclear lamina and plays a critical role in maintaining nuclear architecture, regulating gene expression and modulating chromatin positioning. We have previously shown that $L M N B 1$ gene duplications cause autosomal dominant leukodystrophy (ADLD), a fatal adult onset demyelinating disease. The mechanisms by which increased LMNB1 levels cause ADLD are unclear. To address this, we used a transgenic mouse model where Lamin B1 overexpression is targeted to oligodendrocytes. These mice showed severe vacuolar degeneration of the spinal cord white matter together with marked astrogliosis, microglial infiltration, and secondary axonal damage. Oligodendrocytes in the transgenic mice revealed alterations in histone modifications favoring a transcriptionally repressed state. Chromatin changes were accompanied by reduced expression of genes involved in lipid synthesis pathways, many of which are known to play important roles in myelin regulation and are preferentially expressed in oligodendrocytes. Decreased lipogenic gene expression resulted in a significant reduction in multiple classes of lipids involved in myelin formation. Many of these gene expression changes and lipid alterations were observed even before the onset of the phenotype, suggesting a causal role. Our findings establish, for the first time, a link between LMNB1 and lipid synthesis in oligodendrocytes, and provide a mechanistic framework to explain the age dependence and white matter involvement of the disease phenotype. These results have implications for disease pathogenesis and may also shed light on the regulation of lipid synthesis pathways in myelin maintenance and turnover.

Key words: chromatin; demyelination; gene expression; inflammation; Lamin B1; lipid

\section{Significance Statement}

Autosomal dominant leukodystrophy (ADLD) is fatal neurological disorder caused by increased levels of the nuclear protein, Lamin B1. The disease is characterized by an age-dependent loss of myelin, the fatty sheath that covers nerve fibers. We have studied a mouse model where Lamin B1 level are increased in oligodendrocytes, the cell type that produces myelin in the CNS. We demonstrate that destruction of myelin in the spinal cord is responsible for the degenerative phenotype in our mouse model. We show that this degeneration is mediated by reduced expression of lipid synthesis genes and the subsequent reduction in myelin enriched lipids. These findings provide a mechanistic framework to explain the age dependence and tissue specificity of the ADLD disease phenotype. 


\section{Introduction}

The nuclear lamina is a fibrous meshwork of intermediate filament proteins that is found adjacent to the inner nuclear membrane in multicellular eukaryotic cells (Butin-Israeli et al., 2012; Jung et al., 2013). It not only provides structural integrity to the nucleus but also plays a role in essential cellular processes, such as transcription, DNA replication, DNA repair, and epigenetic regulation (Butin-Israeli et al., 2012; Gerace and Huber, 2012; Jung et al., 2013). There is evidence that genes localized at the nuclear periphery may be subject to transcriptional silencing and lamina associated chromatin is enriched in specific repressive histone marks (Guelen et al., 2008; Stancheva and Schirmer, 2014). In addition, the nuclear lamina has been shown to play an important role in both normal and pathological aging (Haithcock et al., 2005; Ghosh and Zhou, 2014).

Two major kinds of lamins are present in vertebrate cells; the $\mathrm{A}$ and $\mathrm{B}$ types. The A-type lamins, lamins A and C, are alternatively spliced products of the same gene LMNA. Two separate genes, $L M N B 1$ and $L M N B 2$, code for the major B-type lamins (Gerace and Huber, 2012). At least one B-type lamin is thought to be expressed in all somatic cells, whereas lamin A/C is primarily found in differentiated cells (Goldman et al., 2002). Although they closely interact to form the nuclear lamina, the A- and B-type lamins are thought to form distinct microdomains and may have independent functions (Shimi et al., 2008).

We have previously shown that duplications of the LMNB1 gene are responsible for the adult onset demyelinating disease autosomal dominant leukodystrophy (ADLD), the only disease presently associated with LMNB1 mutations (Padiath et al., 2006; Padiath and $\mathrm{Fu}, 2010)$. ADLD is a slowly progressive and fatal adult onset neurological disorder presenting in the fourth or fifth decade of life (Schwankhaus et al., 1994; Coffeen et al., 2000). It is characterized clinically by early autonomic abnormalities, pyramidal and cerebellar dysfunction, muscle wasting, and symmetrical demyelination of the CNS with the brainstem and spinal cord showing early involvement (Schwankhaus et al., 1994; Coffeen et al., 2000; Melberg et al., 2006; Sundblom et al., 2009). A study using brain tissue from multiple sclerosis (MS) patients demonstrated that dysfunctional oligodendrocyte precursor cells had abnormal perinuclear lamin Blaggregates, suggesting a link between lamin B1 and MS (Nakahara et al., 2009).

Recent reports studying fibroblasts from ADLD patients suggest that lamin B1 overexpression may impact nuclear rigidity or RNA splicing (Ferrera et al., 2014; Bartoletti-Stella et al., 2015). Late-onset motor dysfunction reminiscent of ADLD was demon-

Received April 26, 2015; revised June 24, 2015; accepted July 23, 2015.

Author contributions: H.R., Y.Y.T., M.H., A.A.A., L.J.S., Y.L., M.R.H.E., J.D., H.B., V.E.K., P.C., and Q.S.P. designed research; H.R., Y.Y.T., M.H., A.A.A., L.J.S., B.C.N., Y.L., K.L., J.C., R-R.H., P.G., L.H.R., D.J., and Q.S.P. performed research; H.R., Y.Y.T., M.H., A.A.A., L.J.S., B.C.N., Y.L., M.R.H.E., K.L., J.C., L.H.R., J.D., H.B., V.E.K., P.C., and Q.S.P. analyzed data; Q.S.P. wrote the paper.

This project used the UPCI Cancer Biomarkers Facility supported in part by Cancer Center Support Grant (CCSG) P30CA047904. The work was funded in part by grants from the National Institutes of Health-R21AG046897 (QSP), U19A1068021, NS076511 (H.B., V.E.K.), ES020693 (V.E.K., Y.Y.T.), R37NS04295 (P.C.) and National Multiple Sclerosis Society-RG 5045A1 (Q.S.P). M.R.H.E is supported by grants from the National Institutes of Health (CA153114), The University of Texas MD Anderson Cancer Center Institutional Research Grant (IRG) Program, and by MD Anderson's Center for Cancer Epigenetics. Y.L is supported by CPRIT Core Facility 19 Support Grant (RP120348). We would like to thank Dr. Robert D. Nicholls for critical reading of the manuscript and valuable comments and Dr. Zsolt Urban for use of lab facilities. Morgan Jessup is thanked for technical assistance with tissue sectioning.

The authors declare no competing financial interests.

Correspondence should be addressed to Dr Quasar S. Padiath, Department of Human Genetics, Graduate School of Public Health, University of Pittsburgh, Pittsburgh, Pennsylvania 15216. E-mail: qpadiath@pitt.edu.

H. Rolyan's present address: Center for Neuroscience and Regeneration Research, VA, West Haven, and Department of Neurology, School of Medicine, Yale University, С 06515.

DOI:10.1523/JNEUROSCI.1668-15.2015

Copyright $\odot 2015$ the authors $\quad 0270-6474 / 15 / 3512003-16 \$ 15.00 / 0$ strated in mice specifically overexpressing lamin B1 in oligodendrocytes and not in neurons or astrocytes, suggesting that oligodendrocytes are the main cell type involved in the disease process (Heng et al., 2013). This study described a demyelinating phenotype involving the brainstem, analyzed only by electron microscopy, and accompanied by a reduction of the myelin protein, PLP1. However, the authors suggested that PLP1 downregulation was insufficient to explain the ADLD-like phenotypes. As the deficiency of PLP1 in mice does not interfere with myelination (Klugmann et al., 1997; Werner et al., 2013), it seemed unlikely that this alone could be the cause of the disease. Thus, the mechanisms underlying the demyelination in ADLD are still unclear.

To gain further insights into the disease pathology we performed a detailed histopathological and molecular analysis of a similar, independently derived oligodendrocyte-specific transgenic mouse model overexpressing lamin B1. We show that these transgenic mice had severe vacuolar demyelination, axonal damage and neuronal loss, mainly involving the spinal cord that has not been previously reported, that likely leads to premature mortality. This pathology was accompanied by significant epigenetic and lipogenic gene expression alterations resulting in a reduction of myelin-enriched lipids. We hypothesize that lipid dysregulation plays a role in the demyelination, suggesting a novel link between LMNB1 and lipid synthesis in oligodendrocytes.

\section{Materials and Methods}

Generation of transgenic mice. Lamin B1 transgenic mice were generated at the University of Pittsburgh transgenic core on an FVB/N background. A FLAG tag was ligated to the $5^{\prime}$ end of a full-length human lamin B1 cDNA fragment and cloned between the AscI and PacI restriction sites downstream of the murine proteolipid protein 1 (Plp1) promoter cassette as previously described (Fuss et al., 2000; Heng et al., 2013). After injection into $\mathrm{FVB} / \mathrm{N}$ embryos and screening by PCR, two independent founder lines, 1108 and 1081, were established and used for the study and animals of either sex were used in experiments. All animals were housed at University of Pittsburgh animal facilities in accordance with IACUC guidelines.

Behavioral studies: open-field activity monitoring test. Behavioral studies were conducted at the Rodent Behavior Analysis Core of the University of Pittsburgh. All tests were performed in environmentally controlled conditions during the day phase of the light/dark cycle. Three to four WT and transgenic (TG) mice from the ages of 3, 8, and 13 months were used for behavioral testing. Mice were individually tested on an open-field apparatus ( $43 \times 43 \times 30 \mathrm{~cm}$; Med Associates) and allowed to explore the arena freely for $30 \mathrm{~min}$. Horizontal and vertical movements were monitored with infrared light beams and detectors. Beam interruptions were analyzed with custom software (Med Associates) for ambulation, velocity, distance traveled, and rearing.

Tissue processing. For protein, RNA preparation, and lipid/cholesterol analysis, mice were killed, and the brain and spinal cord were quickly removed and stored at $-80^{\circ} \mathrm{C}$ until further use. For histological analysis, mice were anesthetized and intracardiac perfusion performed with icecold $1 \times$ PBS followed by ice-cold 4\% PFA. Brain and spinal cord were removed and postfixed with $4 \%$ formalin followed by cryoprotection with $30 \%$ sucrose at $4^{\circ} \mathrm{C}$. Four micrometer paraffin-embedded or $10 \mu \mathrm{m}$ cryosections were then sectioned for histology and immunostaining.

Immunoblotting. Protein lysates were generated by homogenizing tissues in RIPA buffer containing $1 \times$ complete protease inhibitor cocktail (Roche). Protein concentration was measured by Pierce BCA protein assay kit (Thermo Scientific). Immunoblotting was performed with $\sim 20-50 \mu \mathrm{g}$ of protein for single analysis. Briefly, after acrylamide gel electrophoresis, proteins were transferred to nitrocellulose membranes followed by blocking with $4 \%$ nonfat milk in TBS-T for $1 \mathrm{~h}$ at RT. Membranes were incubated with primary antibodies diluted in $4 \%$ nonfat milk for overnight at $4^{\circ} \mathrm{C}$. After washing membranes were incubated with 
HRP-labeled donkey secondary antibodies (Jackson Immunoresearch) diluted in $4 \%$ nonfat milk for $1 \mathrm{~h}$ at room temperature followed by washing and development using chemiluminescence kits (Thermo Scientific).

Histology and immunostaining. Histology and immunostainings were done with standard protocols. Briefly, cryosections were washed with $1 \times$ TBS buffer followed by blocking with 5\% normal donkey serum, 2\% BSA (Jackson Immunoresearch) and $0.25 \%$ Triton X-100 for $1 \mathrm{~h}$ at RT and incubated with primary antibodies diluted in the blocking buffer for overnight at $4^{\circ} \mathrm{C}$. In some cases, sections from the spinal cord were rehydrated in PBS for 10 min and incubated in $10 \mathrm{~mm}$ citrate buffer, $\mathrm{pH}$ 6.0, at $65^{\circ} \mathrm{C}$ during $1 \mathrm{~h}$ for antigen retrieval. After TBS washes, sections were incubated with fluorescently labeled goat secondary antibodies (Jackson Immunoresearch) for $1 \mathrm{~h}$ at RT and unbound antibody was removed by washing with TBS. Fluoromyelin staining (Life Technologies) was performed on cryosections as per the manufacturer's instructions. All cryosections were mounted with DAPI mounting media (H-1200, Vector Laboraties) and imaged with a Leica DM5000 microscope. For staining paraffin embedded sections, sections were deparaffinized and rehydrated followed by antigen retrieval with $10 \mathrm{~mm}$ citrate buffer and microwave boiling $\mathrm{H} \& \mathrm{E}$ staining was done on paraffin embedded sections as per the manufacturer's instructions (American MasterTech Scientific). TG and WT sections were mounted adjacent to each other on the same slide and immunostaining was performed on the whole slide. This ensured that immune-staining conditions were identical across TG and WT sections, thus eliminating differences in labeling efficiency. Imaging was performed using identical settings between WT and TG sections to ensure that results across these sections could be compared.

TUNEL assays to identify apoptotic nuclei were performed on paraffin sections using the ApopTag Peroxidase In Situ Apoptosis Detection Kit (S7100, Millipore) with human tonsil as a positive control.

Immunostaining for chromatin modifications. Ten micrometer tissue sections from the spinal cord were rehydrated in PBS for $10 \mathrm{~min}$ and incubated in $10 \mathrm{~mm}$ citrate buffer, $\mathrm{pH} 6.0$, at $65^{\circ} \mathrm{C}$ during $1 \mathrm{~h}$ for antigen retrieval. The slides were washed in PBS and equilibrated with blocking solution (PGBA, 10\% normal goat serum, $0.5 \%$ TX-100) during 30 min, before proceeding with primary antibodies probing overnight at $4^{\circ} \mathrm{C}$. This was followed by appropriate secondary antibody incubation for $1 \mathrm{~h}$ at room temperature. The tissue was counterstained with $4^{\prime}, 6^{\prime}$ diamidino-2-phenylindole (DAPI; 1:10,000; Invitrogen) to visualize the cell nuclei. Stained tissue (from at least 3 different animals) was imaged in at least three different fields using a LSM710 confocal microscope (Zeiss). The intensity of $\mathrm{H} 3 \mathrm{~K} 9 \mathrm{me} 3, \mathrm{H} 3 \mathrm{~K} 27 \mathrm{me} 3, \mathrm{AcH} 3$, and $\mathrm{AcH} 4$ fluorescence staining was measured in arbitrary units using NIH ImageJ software.

Antibodies. The following antibodies were used in this study: FLAG (F7425, F4042 both from Sigma-Aldrich), Lamin B1 (ab16048, Abcam; 33-2000, Invitrogen; sc-6217, Santa Cruz Biotechnology), APC/CC-1 (OP 80, Millipore), GFAP (MAB360, Millipore), Iba-1 (019-19741, Wako), NeuN (MAB377, Millipore), APP (512700, Invitrogen), PLP (MAB388, Millipore), MBP (sc-13914, Santa Cruz Biotechnology; MAB384, Millipore), MAG (34-6200, Invitrogen), MOG (sc-73330, Santa Cruz Biotechnology), CNPase (NE1020, Millipore), $\beta$-actin (MA515739, Pierce), GAPDH (MA515738, Pierce), acetylated histone 3 (Millipore 06-599, 1:200); acetylated histone 4 (Millipore 06-866, 1:200), tri-methyl K9 histone 3 (Abcam ab8898, 1:400); tri-methyl K27 histone 3 (Millipore 07-449, 1:200), CC1 (APC, Calbiochem OP-80, 1:50); HMGCR (Abcam, ab174830), and FASN (Abcam, ab22759). Secondary polyclonal antibodies were either goat (fluorescence, cross absorbed) or donkey (HRP) from Jackson Immunoresearch.

Electron microscopy. Mice were deeply anesthetized with $2^{\prime} 2^{\prime} 2^{\prime}$ tribromoethanol and transcardially perfused with $0.1 \mathrm{~m}$ Millonigs buffer containing $4 \%$ paraformaldehyde and 5\% glutaraldehyde. Following a 2 week postfixation, brain and spinal cords were harvested and processed for electron microscopic analyses as previously described (Shroff et al., 2009). Briefly, tissue samples were fixed with $2 \%$ osmium tetroxide, dehydrated by serially dilutions of ethanol, and embedded in PolyBed (Polysciences). All samples were sectioned at $1 \mu \mathrm{m}$ and $90 \mathrm{~nm}$, stained with toluidine blue, and a uranyl acetate and lead citrate, respectively, and imaged using a JEOL transmission electron microscope equipped with an Orius SC1000 CCD camera (Gatan). For spinal cord analysis, cervical levels C3-C5 were embedded for cross sectional analysis while levels C6-C8 were embedded for longitudinal analysis. For the brain sections, a longitudinal brain matrix was used to cut a $1 \mathrm{~mm}$ midsagittal section and a coronal brain matrix was used to cut a $1 \mathrm{~mm}$ coronal section. These sections were embedded to analyze cross and longitudinally oriented myelinated axons from the corpus callosum. For the spinal cord, the cervical region was harvested and cut into two pieces at the cervical level 4. Cervical levels 1-4 were used for longitudinal analysis while the region spanning cervical levels 5-8 were used for cross sectional analysis. All analyses were conducted at the level of the fornix. For spinal cord, corpus callosum, and brainstem samples, cross sections were used for quantitation of the extent of myelin formation and stability by capturing 10 images. Longitudinal sections were used to assess node/ paranode structure. Integrity of the myelinated axons was quantified at the electron microscopy (EM) level as previously described (Dupree et al., 2015).

RNA extraction, QT-PCR analysis, and RNA-seq. RNA from mouse tissues was isolated with Trizol (Life Technologies) using the manufacturer's protocol. cDNA was synthesized using M-MuLV first strand cDNA synthesis kit (New England BioLabs). QT-PCR was performed on a ABI 7900HT real-time thermocycler (Life Technologies) and analyzed using the $\Delta \Delta C_{\mathrm{T}}$ method (Livak and Schmittgen, 2001) and normalized to $\beta$-actin as the internal control.

RNA-Seq was performed at the Tufts University Core Facility Genomics Core on an Illumina HiSeq 2500. Three biological replicates were prepared for WT and TG genotypes for each time point.

RNA-Seq analysis. Total RNA samples were processed at the Tufts University Core Facility Genomics Core for RNA-Seq analysis. Briefly, the integrity and concentration of total RNA was determined by an Agilent BioAnalyzer 2100 and/or Advanced Analytical (AA) Fragment Analyzer. High-integrity total RNA $(0.5-1 \mu \mathrm{g})$ from each sample was used as input material for library preparation using Illumina TruSeq Stranded mRNA Sample Prep kit per the manufacturer instructions. The molar concentration of each library was then quantified on the AA Fragment Analyzer and mixed at equal molar to form a multiplexed library. The next generation sequencing of this multiplexed library was then performed on an Illumina HiSeq 2500 using high-output SBS V3 chemistry using single read 100 bases format. The resulting raw sequence was then de-multiplexed by the CASAVA 1.8 software and yielded results in fastq format. Three biological replicates were prepared for WT and TG genotypes for each time point. A total of 12 libraries were sequenced generating 17-22 million reads per sample. The reads were mapped to the mouse genome (mm10) by TopHat (v2.0.9; Kim et al., 2013). The overall mapping rate was $>90 \%$ for all the samples. The number of reads for each known gene from the RefSeq database (Pruitt et al., 2012; downloaded from UCSC Genome Browser on March 6, 2013) was enumerated using htseq-count from HTSeq package (v0.5.3p9; Anders and Huber, 2010). The differential expression between conditions was statistically assessed by R/Bioconductor package DESeq [4] (v1.10.1). Genes with false discovery rate $\leq 0.05$ were called differentially expressed.

Liquid chromatography-mass spectroscopy for lipid/cholesterol measurement. Lipids were extracted by the Folch procedure with slight modifications, under nitrogen atmosphere, at all steps (Folch et al., 1957). LC/ ESI-MS analysis was performed on a Dionex HPLC system coupled to a LXQTM ion trap mass spectrometer (ThermoFisher Scientific) with the Xcalibur operating system, as previously described (Tyurina et al., 2011). Cholesterol was analyzed from total lipid extracts by reverse-phase chromatography with some modifications (Agilent Technologies, Appl Note no. 5991-0452EN, 2012).

Separation of phospholipids was performed on a Luna $3 \mu \mathrm{m}$ Silica (2) $100 \AA 150 \times 1 \mathrm{~mm}$ column (Phenomenex) at a flow rate of $50 \mu \mathrm{l} / \mathrm{min}$ using gradient of solvent $A$ (hexane:propanol:water, 47:57:1, v/v) and solvent B (hexane:propanol:water, 47:57:10, v/v) each containing $5 \mathrm{~mm}$ ammonium acetate and $0.01 \%$ formic acid as follows: $0-3$ min, linear gradient, $10-37 \%$ solvent $\mathrm{B} ; 3-12.5 \mathrm{~min}$, isocratic at $37 \%$ solvent $\mathrm{B}$; $12.5-20 \mathrm{~min}$, linear gradient, $37-100 \%$ solvent $\mathrm{B} ; 20-45 \mathrm{~min}$, isocratic at $100 \%$ solvent $\mathrm{B} ; 45-60 \mathrm{~min}$, isocratic at $10 \%$ solvent $\mathrm{B}$. The instrument was operated in the negative ion mode (at a voltage differential of -3.5 to 
$-5.0 \mathrm{kV}$, source temperature was maintained at $\left.150^{\circ} \mathrm{C}\right) . \mathrm{MS}^{\mathrm{n}}$ analysis was performed with relative collision energy ranging from 20 to $40 \%$ and with activation $q$ value at 0.25 for collision-induced dissociation and $q$ value at 0.7 for pulsed-Q dissociation technique using an isolation width of $1 \mathrm{~m} / z, 5$ microscans with a maximum injection time of $1000 \mathrm{~ms}$. Identified lipids were quantitated using appropriate internal standards from Avanti Polar Lipids.

For cholesterol analysis a Luna C8 column [4.6 mm (i.d.) $\times 15 \mathrm{~cm}, 5$ $\mu \mathrm{m}$, Phenomenex] was used on a Dionex Ultimate 3000 HPLC system (Thermo Scientific). The column compartment was maintained at $35^{\circ} \mathrm{C}$. An isocratic solvent system was used consisting of $80 \%$ acetonitrile/20\% methanol containing $0.1 \%$ ammonium hydroxide. Flow was maintained at $0.5 \mathrm{ml} / \mathrm{min}$. Electrospray ionization mass spectrometry was performed on a hybrid quadrupole-orbitrap mass spectrometer (Q-Exactive, Thermo Scientific). Analysis was performed in positive ion mode at a resolution of 140,000 for the full MS scan and 17,500 for the MS2 scan in a data-dependent mode. The scan range for MS analysis was 350-410 $\mathrm{m} / z$ with a maximum injection time of $512 \mathrm{~ms}$ using 1 microscan. A maximum injection time of $60 \mathrm{~ms}$ was used for $\mathrm{MS}^{2}$ (high-energy collisional dissociation) analysis with collision energy set to 24 . An isolation window of $1.0 \mathrm{Da}$ and $0.5 \mathrm{Da}$ was set for the MS and MS2 scans, respectively. Capillary spray voltage was set at $4.5 \mathrm{kV}$, and capillary temperature was $380^{\circ} \mathrm{C}$. Deuterated cholesterol (d7) was purchased from Avanti Polar Lipids and used as an internal standard. Cholesterol products were detected as the molecular ion minus water and confirmed by exact mass MS/MS analysis.

MALDI imaging. Frozen cervical spine sections from two WT and two TG animals ( 3 months) were embedded in gelatin solution $(8 \% \mathrm{w} / \mathrm{v}$ in HBSS without calcium or magnesium) in cryostat molds, cooled on ice to solidify and frozen at $-20^{\circ} \mathrm{C}$. Embedded blocks were sectioned $\left(-28^{\circ} \mathrm{C}\right.$, $7 \mu \mathrm{m})$ and analyzed as described previously with slight modifications (Amoscato et al., 2014). Matrix-assisted laser desorption/ionizationmass spectrometry (MALDI-MS) imaging analyses (reflector mode, positive-ion polarity, $\mathrm{m} / z 340-3000$ ) were performed using an Ultraflex II axial-TOF/TOF mass spectrometer (Bruker Daltonics) equipped with a $337 \mathrm{~nm}$ wavelength $\mathrm{N}_{2}$ laser $(50 \mathrm{~Hz}$ pulse rate). Paired WT and TG sections were simultaneously inserted into the mass spectrometer and analyzed sequentially on the same day.

MALDI-MS images (50 $\mu \mathrm{m}$ lateral resolution, 20 laser shots per location) were produced using FlexImaging 4.0 software (Bruker Daltonics). Heat maps for a given mass/charge $(\mathrm{m} / \mathrm{z})$ value $\pm 0.25 \mathrm{Da}$ were generated with a noise cutoff of $2.5 \%$ of the strongest intensity ion. Lipid identification was based on theoretical monoisotopic mass values. Images of the same ion from the paired WT and TG tissues were normalized to $100 \%$ of the maximum intensity of the WT ion, rendered to 12 bit depth and additive combinations were made using Nikon Elements software.

Statistics. Student's $t$ tests were used to calculate statistical significance between two groups and a $p$ value $<0.05$ was considered statistically significant. For tests that involved multiple treatments, one-way ANOVA followed by Tukey's post hoc tests to compare significance between individual treatments were carried out. The following convention for representing $p$ values was followed: ${ }^{*} p<0.05,{ }^{* *} p<0.01,{ }^{* * *} p<0.001$. All graphs were plotted as mean values with error bars representing SEM unless otherwise specified.

\section{Results \\ Degeneration of spinal cord white matter in Plp-FLAG-LMNB1 mice}

To study the effect of lamin B1 overexpression on oligodendrocyte function and disease progression, we independently generated transgenic mice where the expression of a FLAG tagged human lamin B1 cDNA construct was driven by the mouse Plp1 promoter (Plp-FLAG-LMNB1). Mice derived from the same construct, also on an FVB/N background, have been previously described (Heng et al., 2013). Plp1 is a gene highly expressed in mature CNS oligodendrocytes and this promoter construct has been previously used to localize expression of target genes to this specific cell type (Fuss et al., 2000).
Immunoblotting of protein lysates from different regions of the CNS revealed that the overexpression of the FLAG tagged lamin B1 was maximal in the spinal cord (Fig. $1 A, B$ ). This was consistent with the report that first described use of the PLP1 promoter expression cassette (Fuss et al., 2000). Using immunohistochemistry (IHC) on brain sections, we confirmed that the exogenous FLAG-tagged lamin B1 colocalized with the endogenous lamin B1 and was correctly targeted to mature oligodendrocytes by showing colocalization with CC1 (Fig. 1C). As the FLAG tag was fused to the lamin B1 cDNA in the transgenic construct, we observed that all FLAG-positive cells were also lamin B1positive, and the majority of FLAG-positive cells were also positive for CC1 $(92 \% \pm 5 \%, n=11$ animals, $>50$ cells per animal were counted). The FLAG tag did not colocalize with neurons or astrocytes (Fig. 1C). Plp-FLAG-LMNB1 TG mice appeared normal at birth but showed severe age-dependent motor dysfunction, kyphosis, and forelimb paralysis and atrophy (Fig. 1D,E; Movie 1) and did not survive beyond $\sim 15$ months, consistent with the phenotype described previously (Heng et al., 2013).

To identify the pathology underlying the age-dependent motor dysfunction in the TG mice we performed histological analysis of different CNS regions at three different time points $(3,8$, and 13 months) using standard H\&E staining and the myelinspecific stain, Fluoromyelin. The spinal cord exhibited severe vacuolar degeneration specific to the white matter in the ventral and lateral regions of the cord only in TG mice and was most severe at the later time points. (Fig. $2 A-C$ ). This degenerative phenotype was most pronounced in the cervical region, whereas less-severe changes were observed in the thoracic segments of the spinal cord. The spinal cord had not been examined in the previous report analyzing lamin B1 overxpressing mice (Heng et al., 2013). We also analyzed the brainstem as this was the region previously implicated, but it showed minimal involvement (Fig. $2 D, E)$. Cerebellum and corpus callosum did not show any pathological changes (data not shown). These results suggested that the spinal cord pathology was the underlying cause of the agedependent motor dysfunction and paralysis seen in the PlpFLAG-LMNB1 mice. All further experiments were therefore performed using spinal cord samples.

Analysis of oligodendrocyte number in the spinal cord of TG mice showed no reduction in cell number compared with WT animals at any of the three time points studied (Fig. $2 F, G$ ). On the contrary, we observed statistically significant increases in oligodendrocyte number at 8 and 13 months in the TG mice (Fig. $2 G$ ). TUNEL assays for the detection apoptotic nuclei revealed no staining in either TG or WT spinal cords at 13 months (Fig. 2H). These results would suggest that lamin B1 overexpression does not impact oligodendrocyte survival and we interpreted increased cell counts as an attempt to recruit additional oligodendrocytes to repair the demyelination injury in the TG spinal cords.

IHC analysis of the cervical spinal cord using an anti-NeuN antibody showed loss of neuronal cell bodies in the ventral horn of the 13-month-old TG spinal cord (Fig. 3A,E). Using an amyloid precursor protein (APP) antibody, a marker for axonal degeneration, punctate staining was also observed only in the 13-month-old TG animals (Fig. 3B,E). This would suggest that neuronal loss and axonal degeneration are secondary to the vacuolar degeneration of the white matter as they were not seen at the earlier time points but are likely major contributors to the paralysis and premature mortality. IHC analysis using specific markers also revealed significant microglial/myeloid infiltration and astrogliosis in the TG spinal cord (Fig. 3C-E). Microgliosis, 
A
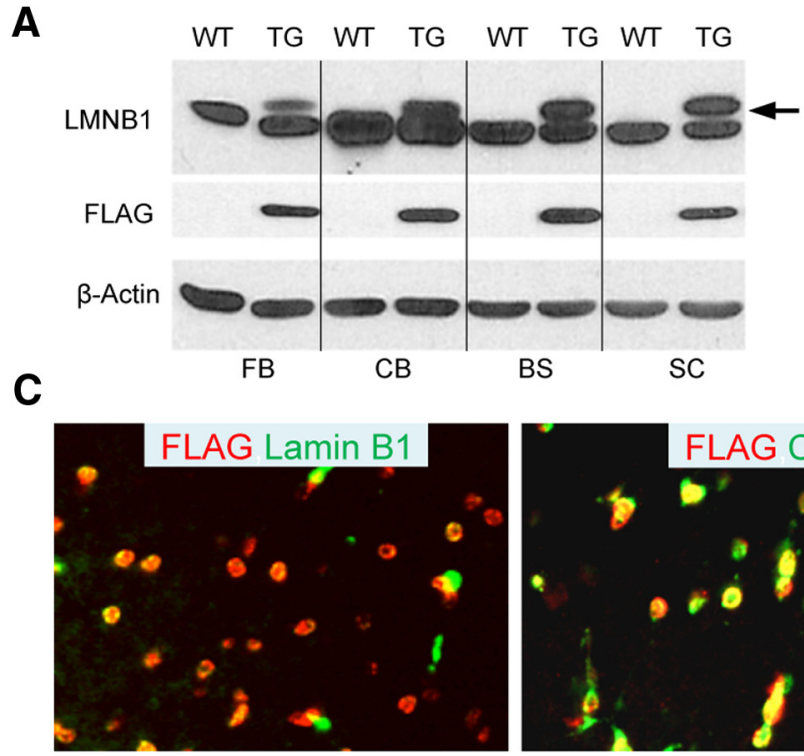

LMNB1

FLAG

$\beta$-Actin

c

D
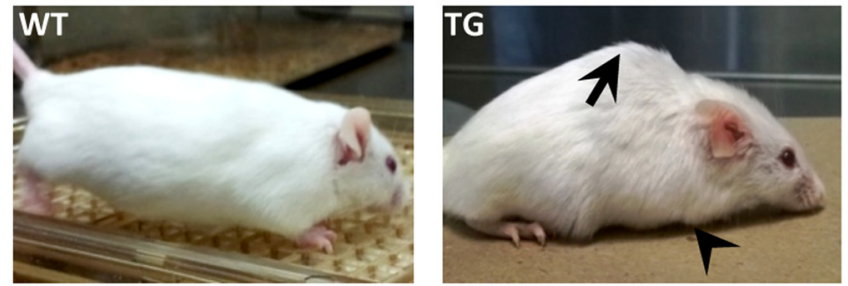

B

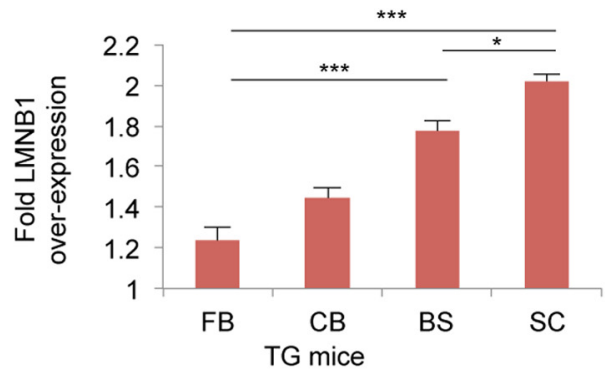

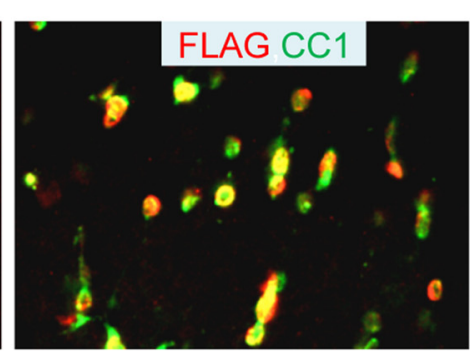

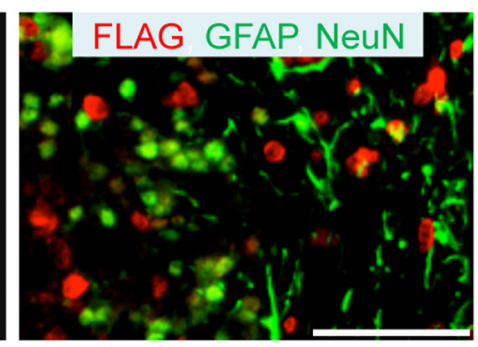

E

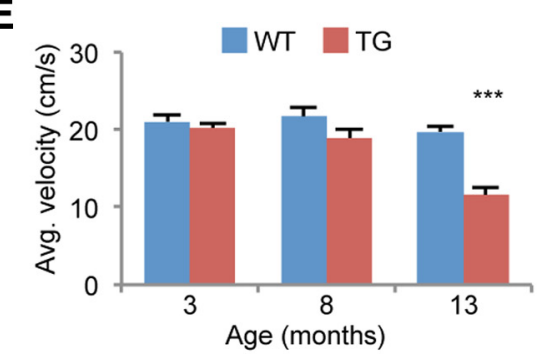

Figure 1. PIp-FLAG-LMNB1 TG mice show accurately targeted exogenous lamin B1 expression and age-dependent motor dysfunction. $A$, Representative immunoblot of TG and WT protein lysates from different CNS regions showed the presence of the FLAG tagged LMNB1 band (arrow) that migrated slightly higher than the endogenous LMNB1 protein. This higher band and the band in the FLAG immunoblot were present only in the TG samples. FB, Forebrain; BS, brainstem; CB, cerebellum; SC, spinal cord. B, Quantitation of immunoblot data revealed overexpression of LMNB1 was highest in the spinal cord. The ratio of the top lamin B1 band intensity to the total lamin B1 (both top and bottom) band intensities were plotted for the TG samples. Data plotted were mean \pm SEM; ${ }^{*} p<0.05,{ }^{* *} p<0.01,{ }^{* * *} p<0.001 ; n=3$ TG animals per CNS region. C, IHC from brain sections of TG mice showed the colocalization of FLAG (red) and LMNB1 (green) staining. Colocalization was also observed with FLAG (red) and the oligodendrocyte maker, CC1 (green). However, no colocalization is observed between FLAG (red) with the neuronal marker, NeuN (green), and astrocyte marker GFAP (green). Scale bar, $50 \mu \mathrm{m}$. D, WT 13-month-old mice showed no obvious phenotype, whereas TG littermate showed kyphosis (arrow) and forelimb atrophy (arrowhead). E, Open-field activity analysis shows a significant reduction in average velocity in the 13-month-old TG mice. Data plotted are mean \pm SEM; ${ }^{* * *} p<0.001$; $n=3-4$ animal per genotype per time point.

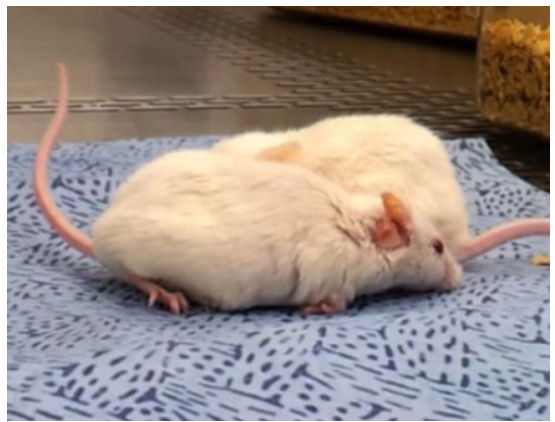

Movie 1. Motor dysfunction and forelimb paralysis in PLP-FLAG-LMNB1 mice. Video showing ataxia, forelimb paralysis, and atrophy in PLP-FLAG-LMNB1 that are $\sim 14$ months old.

as evidenced by an increase in Iba-1-positive cells, was localized to the lateral and ventral white matter regions of the spinal cord involved in degenerative phenotype in the 13-and 8-month-old TG animals (Fig. 3C,E). In the case of the GFAP staining, not only did we observe an increase in number of cells showing staining in the 13-month-old TG animals (Fig. 3D,E), we also saw a redistribution of reactive astrocytes toward the gray matter.
Electron microscopy reveals significant age-dependent demyelination in spinal cords of Plp-FLAG-LMNB1 mice Consistent with the histopathological data, the most dramatic pathology on EM imaging was seen in the cervical spinal cord of the 13-month-old TG mice compared with WT (Fig. 4A-C). These EM images showed loss of general organization of myelinated axons with widespread myelin and axonal degeneration. We observed high levels of astrogliosis, very thin myelin (suggestive of remyelination), redundant myelin, and unmyelinated axons. Phagocytic cells and myelin debris were commonly observed (Fig. $4 D$ ). Large vacuoles were commonly observed with (Fig. $4 B$, black box) and without (Fig. $4 B$, asterisk) an axon. These vacuoles are consistent with those described in the TG spinal cord H\&E sections (Fig. $2 A$ ) and with previous studies of lipid mutants that revealed swelling of the periaxonal space and occasionally accompanied by complete degeneration of the axon (Coetzee et al., 1996; Dupree et al., 1998). Spinal cords from 8-month-old TG mice showed similar changes to the 13-month-old samples, although they were less severe (Fig. 4D). EM analysis of brainstem from 13-month-old TG mice showed much milder pathology compared with the spinal cord (data not shown). EM images of 3-month-old TG mice were indistinguishable from the WT controls (Fig. 4E,F). Longitudinal sections from 13-month-old TG 
A

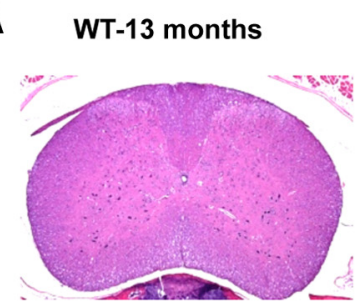

B
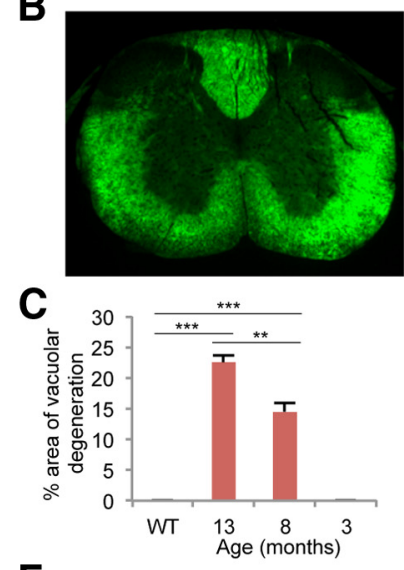

F

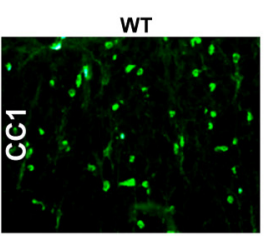

TG-13 months
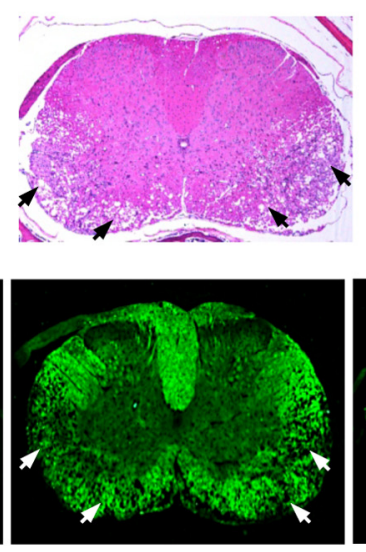

D

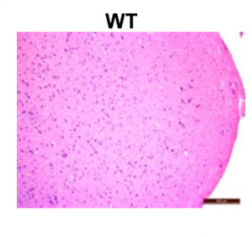

TG-8 months
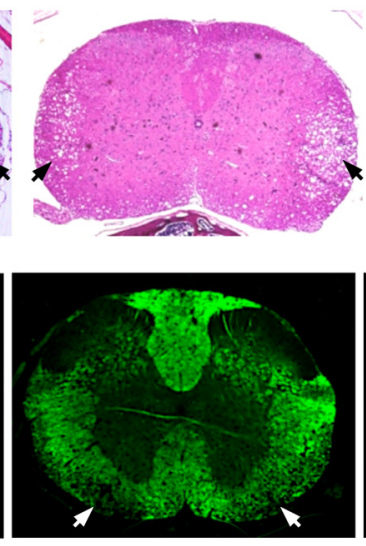

E

TG
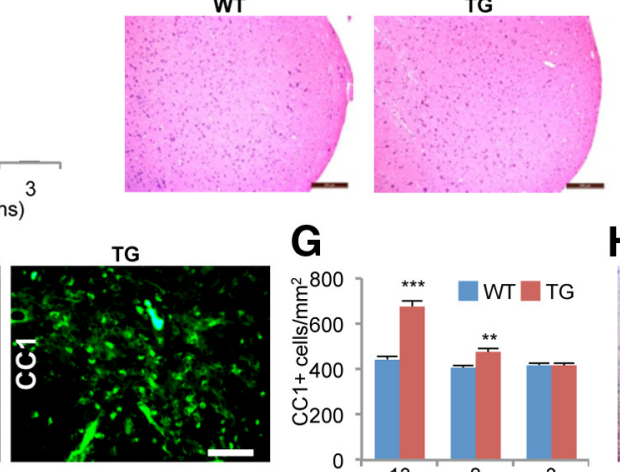

G

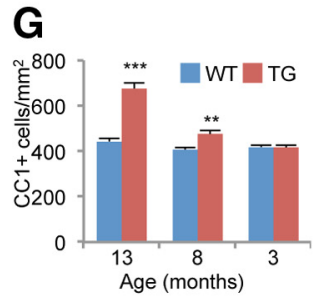

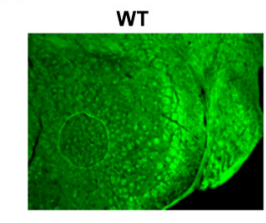

H

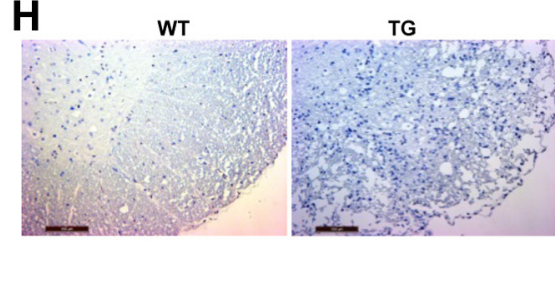

Figure 2. PIp-FLAG-LMNB1 TG mice show age-dependent degeneration of the spinal cord white matter. $\boldsymbol{A}$, Representative H\&E staining of WT and TG spinal cord sections. TG sections showed severe vacuolar degeneration of ventral and lateral white matter regions (arrows) at the 13 and 8 month time points. Three month TG sections do not show any obvious pathology. $\boldsymbol{B}$, Representative Fluoromyelin staining of WT and TG spinal cord sections. TG sections showed a loss of staining in ventral and lateral white matter regions (arrows) only at the 13 and 8 month time points. Scale bars: $A, B, 500 \mu \mathrm{m}$. C, Quantitation of vacuolar degeneration from H\&E sections. The ratio of the area involved in vacuolar degeneration relative to the total area of the spinal cord was plotted. Note that no vacuolar degeneration was observed in the WT or 3 month TG samples. Data plotted are mean \pm SEM; ${ }^{* *} p<0.01,{ }^{* * *} p<0.001 ; n=3$ animal per genotype per time point. $\boldsymbol{D}$, Representative H\&E staining of 13 month WT and TG brainstem sections. $\boldsymbol{E}$, Representative Fluoromyelin staining of 13 month WT and TG brainstem sections. No obvious degeneration is observed in the brainstem. Scale bars: D,E, $200 \mu \mathrm{m}$. F, Representative images of CC1 + cells in TG and WT spinal cords. Scale bar, $50 \mu \mathrm{m}$. G, Quantitation of CC1 + cells in TG and WT spinal cord sections across three time points revealed statistically significant increases in oligodendrocyte number in TG animals at the 13 and 8 month time points. ${ }^{* *} p<0.01,{ }^{* * *} p<0.001 ; n=3$ animals per genotype per time point. $\boldsymbol{H}$, Representative images of TUNEL staining for apoptotic nuclei in 13 month TG and WT spinal cord sections. No TUNEL-positive cells were observed in either of the samples. Scale bars, $100 \mu \mathrm{m}$.

mice revealed intact nodal and paranodal structure including the preservation of transverse bands (data not shown); however, as demyelination progressed, the nodal region was disrupted, suggesting that the initial demyelinating event was not dependent on nodal/paranodal deterioration.

\section{Age-dependent chromatin alterations in PLP-FLAG-LMNB1 oligodendrocytes}

The nuclear lamina plays an important role in chromatin positioning and genes within lamina associated domains usually exhibit repressive histone marks and a reduction in transcriptional activity (Guelen et al., 2008). Histone modifications and specifically histone methylation and acetylation play an important role in regulating oligodendrocyte function (Shen et al., 2008; Liu et al., 2015). We therefore sought to determine whether LMNB1 overexpression in oligodendrocytes resulted in altered histone modifications. We observed a significant increase in the repressive histone marks H3K9me3 and H3K273me3 in TG oligodendrocytes at both 3 and 13 month time points compared with WT cells (Fig. 5A,B). Interestingly, these marks showed dynamic changes with age only in the TG animals, with $\mathrm{H} 3 \mathrm{~K} 9 \mathrm{me} 3$ inten- sities increasing in older animals (Fig. 5A), whereas H3K27me3 levels were reduced with age (Fig. $5 B$ ). These age-dependent changes were not observed in oligodendrocytes from WT animals (Fig. $5 A, B$ ). We then analyzed the acetylated histone marks (associated with transcriptionally active genes), AcH3 and AcH4. Although we did not observe any differences between the 3-month-old TG and WT animals, we observed significantly reduced $\mathrm{AcH} 3$ and $\mathrm{AcH} 4$ levels in the TG animals at 13 months (Fig. 5C,D). These results suggest that increased LMNB1 levels are associated with age-dependent chromatin modifications that favor transcriptional repression in the oligodendrocytes of TG animals.

\section{PLP-FLAG-LMNB1 mice show age-dependent reduction in} expression of lipid synthesis genes

To elucidate the mechanisms underlying the demyelinating phenotype observed in the PLP-FLAG-LMNB1 mice we performed biochemical analysis on spinal cord tissue from TG and WT mice at different time points. We first focused on the expression of the major myelin proteins as these are commonly implicated in demyelination. To our surprise, we did not see any significant dif- 

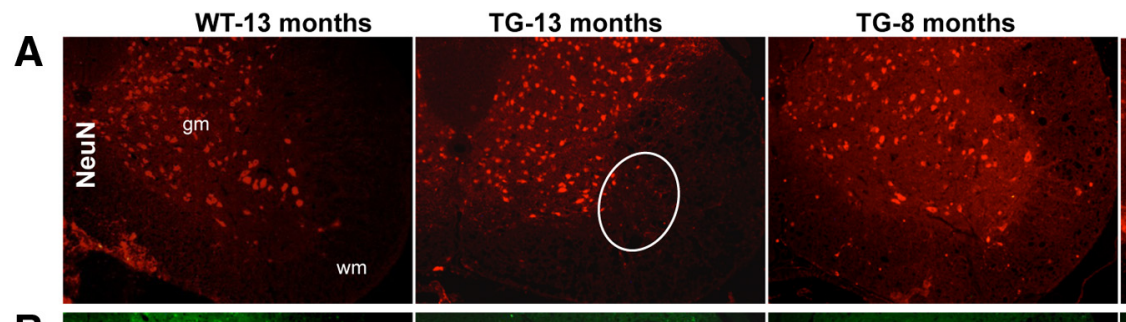

TG-3 months

B

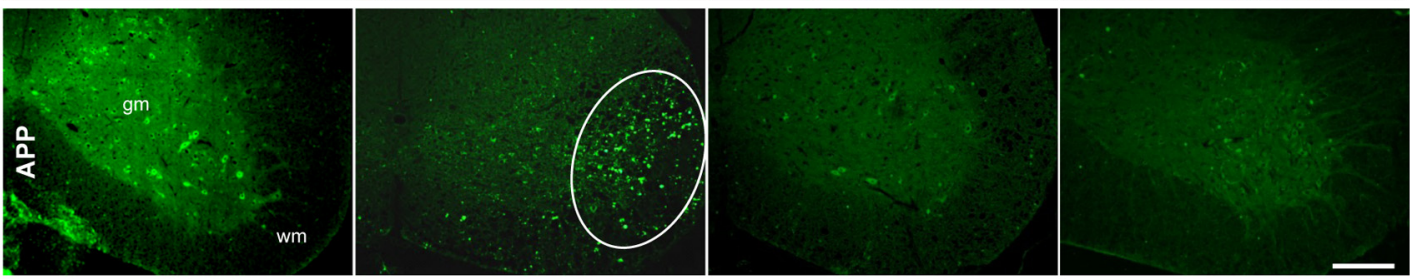

C
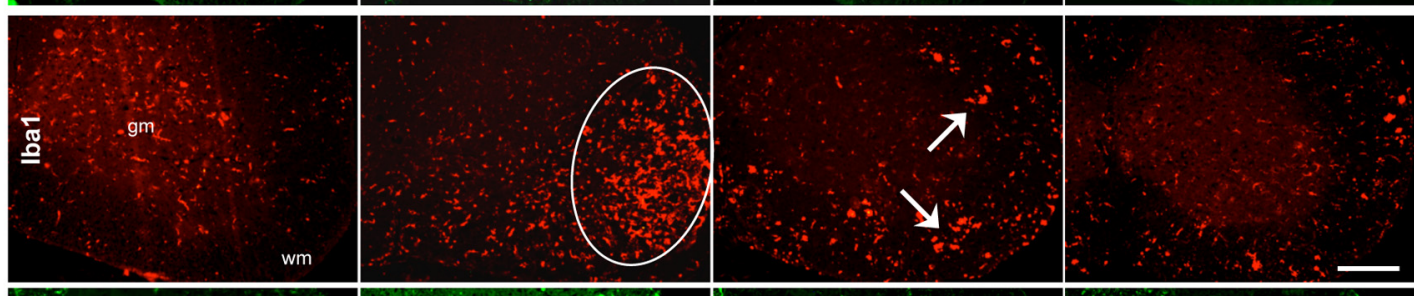

D
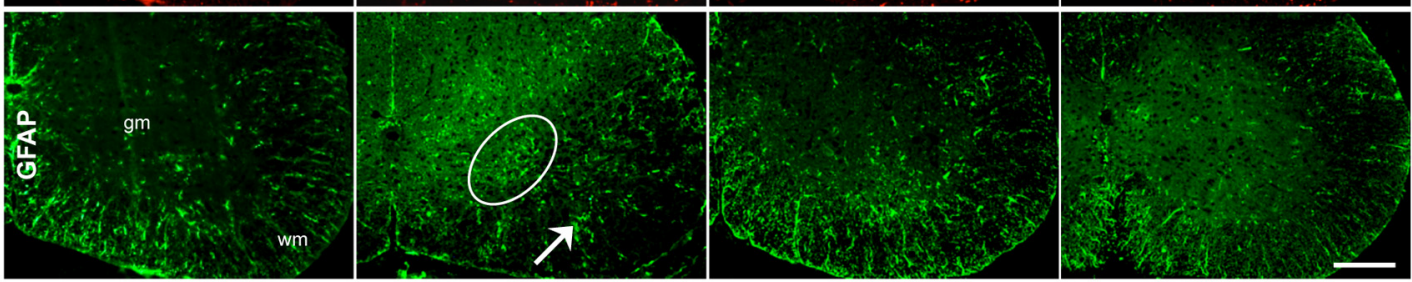

E

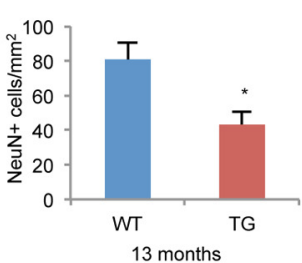

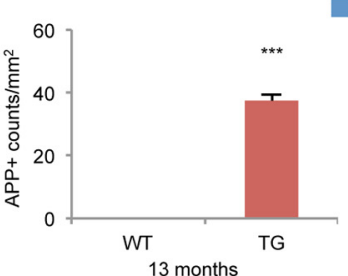

WT $\square$ TG
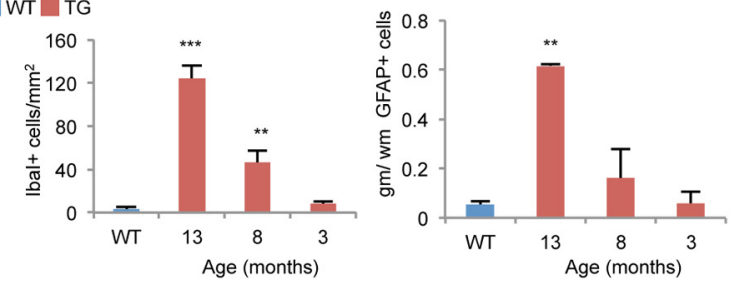

Figure 3. PIp-FLAG-LMNB1 TG spinal cord show secondary neuronal loss, axonal degeneration, astrogliosis, and microglial infiltration. $A$, IHC with the neuronal marker NeuN showed loss of neurons in the ventral horn only in the 13 month TG spinal cord sections (oval region). gm, Gray matter; wm, white matter. $B$, APP, a marker for axonal degeneration, showed increased and punctate staining (oval region) only in the 13 month TG spinal cord sections. C, The microglial marker lba-1 showed significant increase in Ibal + cells in 13 and 8 month TG samples (arrows). D, GFAP staining, a marker for astrocyte infiltration, was increased in the 13 month TG mice (arrow). In these sections, there also appeared to be a reorganization of astrocytes to the gray matter (oval). $S$ Cale bars, 200 $\mu \mathrm{m}$. $\boldsymbol{E}$, Quantitation of histological alterations shown in $\boldsymbol{A}-\boldsymbol{D}$. In all cases, WT was from a 13 month time point. For GFAP quantitation, ratio of GFAP + counts in the gray matter (gm) versus white matter (wm) were plotted. Data plotted are mean $\pm S E M ;{ }^{*} p<0.05,{ }^{* *} p<0.01,{ }^{* * *} p<0.001 ; n=3$ animal per genotype per time point.

ferences in the expression of the major myelin proteins in spinal cord samples from 13-month-old TG and WT mice. We analyzed the expression of MBP, PLP1, CNPase, MAG, and MOG at both the protein and RNA level (Fig. 6A-C). Although we saw slight reductions in the expression of all these genes at the RNA level using quantitative real-time PCR (QT-PCR) these did not reach statistical significance (Fig. 6C).

Given the chromatin alterations we observed in oligodendrocytes of the TG mice and their role in transcriptional regulation, we performed a transcriptomic (RNA-Seq) analysis to identify genes whose expression may be significantly altered between the WT and TG samples. RNA-Seq was performed on spinal cord tissue as this appeared to be the major locus of the pathology. In addition to samples from 13-month-old animals, we also analyzed 3-month-old animals to identify genes that were differentially expressed even before the development of obvious pathology. We reasoned that genes whose expression was consistently altered at both these time points may be causative and oligodendrocyte-specific rather than representing secondary gene expression changes in other cell types in response to demyelination injury.

We identified 322 genes that were differentially regulated between WT and TG animals at 3 months and 2460 genes that were altered at the 13 month time point (Fig. $7 A, B$ ). Of the genes altered at 3 months, the vast majority $(83.9 \%)$, were also common to the 13 month dataset and all showed expression changes in the same direction (Fig. 7A). There was also a dramatic increase in the percentage of genes that were downregulated in the older TG mice from $8.4 \%$ (3 months) to $48.4 \%$ (13 months; Fig. $7 B$ ). Among the genes that were upregulated in the TG animals at both time points, we identified a preponderance that were significantly involved in inflammatory pathways using the Ingenuity Pathway Analysis Software $\left(p=9.4 \times 10^{-46}\right)$. Many of these genes have also shown to be upregulated in other demyelination models, such as experimental autoimmune encephalomyelitis, and we hypothesized that these were probably derived from as- 

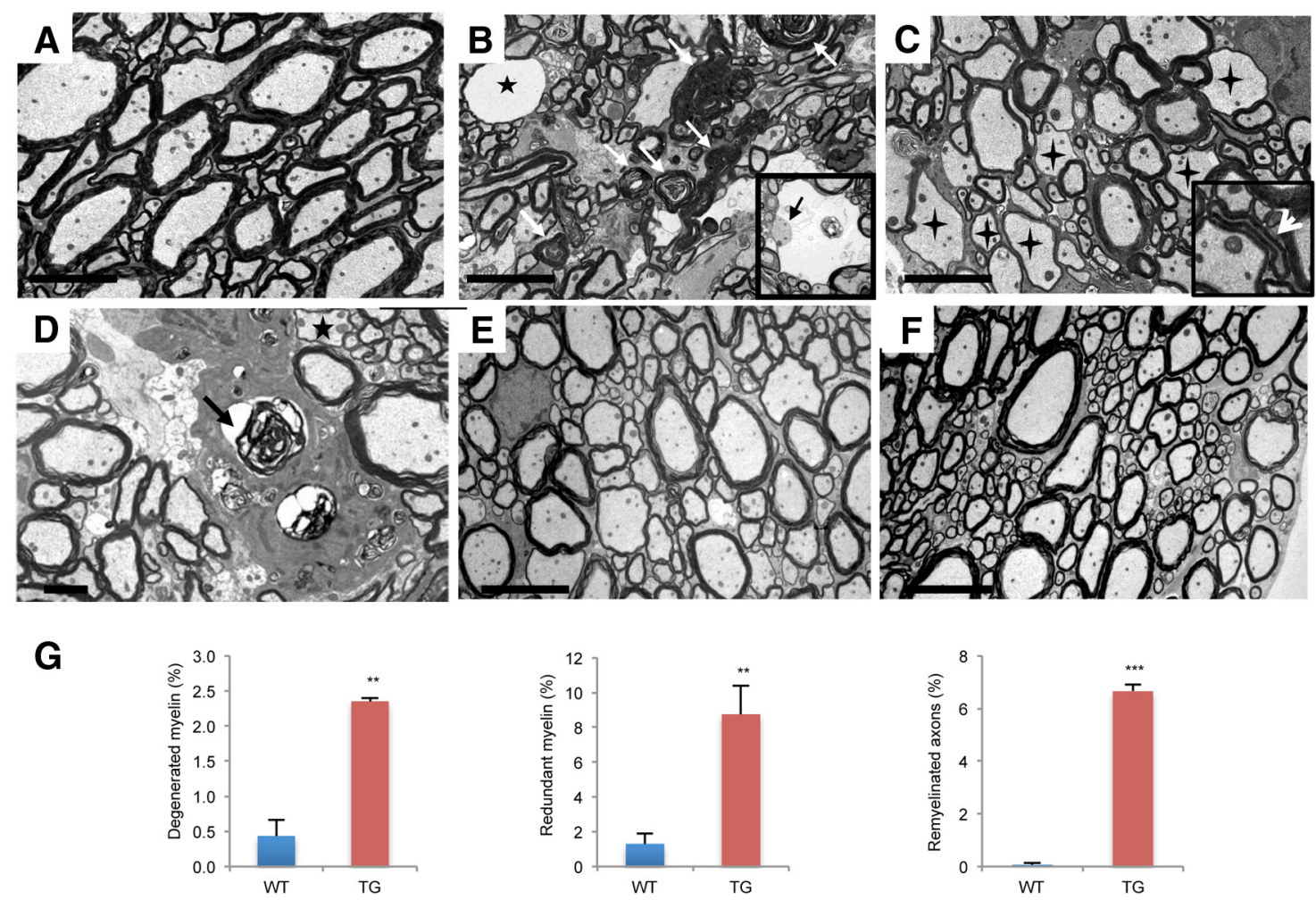

Figure 4. EM of PIp-FLAG-LMNB1 TG spinal cord. A, EM images of 13 month WT spinal cords showed no obvious abnormalities. $B$, C, EM images from 13-month-old TG mice showed severe demyelination and a general loss of organization of myelinated axons. White arrows show degenerating myelin sheaths that remain after axonal loss. Black star shows edematous vacuole without axon. Inset: edematous vacuole with preservation of axon ( $\boldsymbol{B}$, black arrow). Four pointed stars indicate very thinly myelinated axons consistent with remyelination. Inset, $A$ redundant myelin profile is indicated by the white arrowhead (C.D, EM image of an 8 month TG spinal cord shows thinly myelinated axon (black star) and myelin debris engulfed by a phagocyte (black arrow). $\boldsymbol{E}, \boldsymbol{F}$, EM image of a 3 month TG spinal cord shows no obvious pathology $(\boldsymbol{E})$ and is similar to 3 month WT sections $(\boldsymbol{F})$. Scale bars: $\boldsymbol{A}-\boldsymbol{C}, \boldsymbol{E}, \boldsymbol{F}, 10 \mu \mathrm{m} ; \boldsymbol{D}, 2 \mu \mathrm{m}$. $\boldsymbol{G}$, Quantitation of EM alterations in 13 -month-old TG animals. Data plotted are mean \pm SEM; ${ }^{* *} p<0.01,{ }^{* * *} p<0.001$ ( $n=2-3$ animals, $>400$ axons were analyzed per animal).

trocytes or microglia in response to a primary signal from oligodendrocytes. Consistent with our immunoblot and QT-PCR data (Fig. 6A), RNA-Seq analysis did not reveal any significant differences in the expression of genes encoding the major myelin proteins.

Only 12 genes were consistently downregulated between 3 and 13 month samples. Intriguingly, nine of these were identified to be involved in lipid synthesis (Fig. 7C). Furthermore, all these genes, with the exception of Sqle, have been shown to be highly expressed in myelinating oligodendrocytes (Cahoy et al., 2008) suggesting that oligodendrocyte-specific contributions may be primarily responsible for the reduction in lipogenic gene expression. Interestingly, we observed significant increases in the expression of the cholesterol transport gene ApoE in TG mice at the two time points studied using RNA-Seq (Fig. $7 C$ ). This is noteworthy because a similar increase was seen in a mouse model of demyelination where oligodendrocyte-specific cholesterol synthesis was disrupted (Saher et al., 2005).

We also identified a large number of additional genes involved in lipid and cholesterol synthesis whose expression was significantly altered in TG animals at 13 months compared with WT. Of the 499 genes involved in lipid synthesis (GO-0006685), 109 were significantly altered in 13 month TG mice, of which $62 \%$ were downregulated (Fig. 7D). In the case of cholesterol synthesis, (GO-0008610), 38 genes were listed in the pathway, of which 23 were altered at 13 months, with the majority of these being downregulated ( $83 \%$; Fig. $7 D$ ) in TG mice. The proportion of these genes that were downregulated increased even further when we analyzed the subset whose expression is known to be en- riched in myelinating oligodendrocytes using a dataset described previously (Cahoy et al., 2008), strengthening our hypothesis that these changes may be oligodendrocyte specific (Fig. 7D).

QT-PCR analysis with an independent set of RNA samples confirmed that the genes consistently downregulated at the two time points were indeed differentially expressed and showed a dramatic age-dependent decline in their expression in the TG samples (Fig. 8A). Consistent with our results, we observed a decrease in protein levels of one of these genes that we randomly tested in spinal cord lysates from 13-month-old mice (Fig. 8B). We also tested expression levels of fatty acid synthase (Fasn), a gene that has been shown to be previously implicated in lipid synthesis in oligodendrocytes (Lebrun-Julien et al., 2014). We did not identify Fasn in our RNA-Seq analysis but QT-PCR analysis showed a small but significant reduction in expression in TG mice at the later time points (Fig. $8 A$ ). These data were further strengthened by our finding of dramatic reductions in FASN staining in oligodendrocytes in spinal cord sections from 13month-old TG mice (Fig. $8 C$ ). These results suggest that the expression of lipid synthesis genes were downregulated in the LMNB1 overexpressing oligodendrocytes.

The sterol regulatory element binding proteins (SREBP) are a group of transcription factors that play central and overlapping roles in regulating the expression of genes involved in lipid metabolism. Three mammalian SREBP isoforms, SREBP1a, SREBP1c (alternatively spliced isoforms of the Srebf1 gene), and SREBP2 (encoded by Srebf2) have been described. SREBP1a activates fatty acid and cholesterol synthesis, SREBP1c fatty acid 

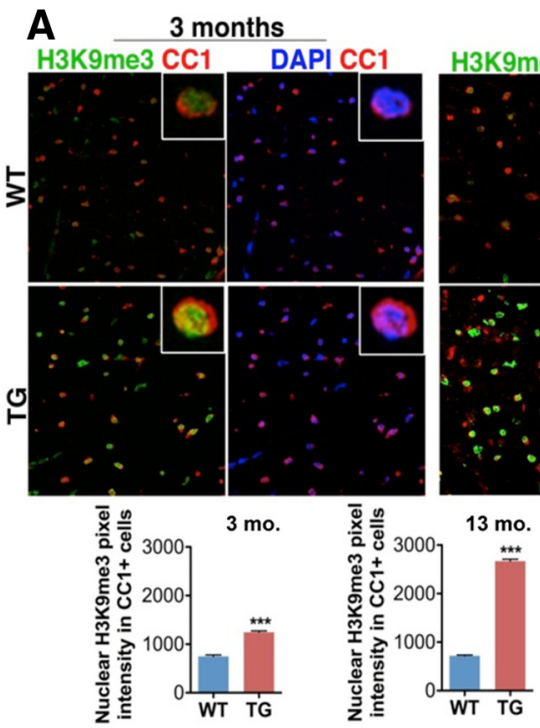

C
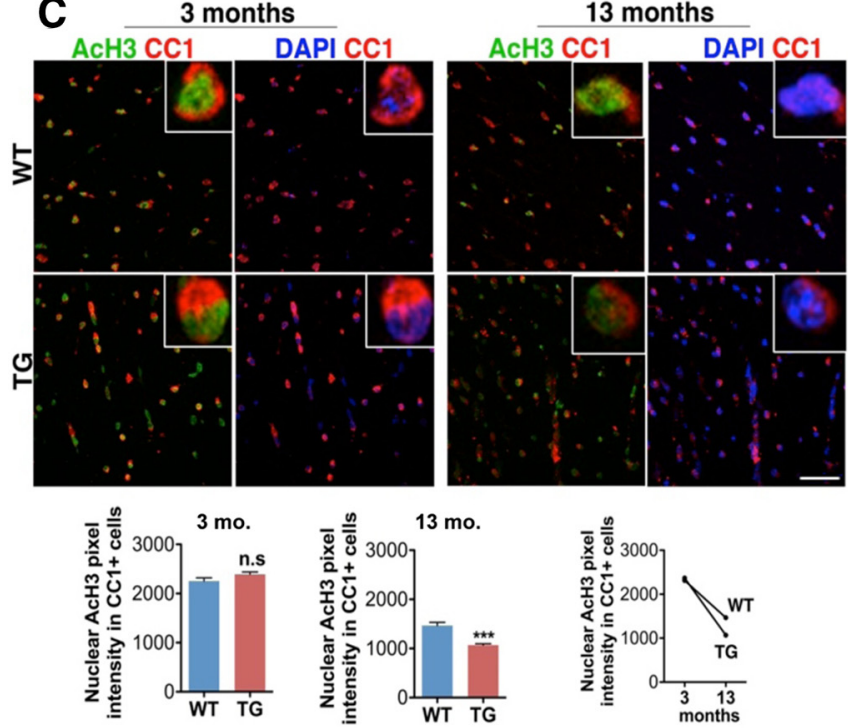

B
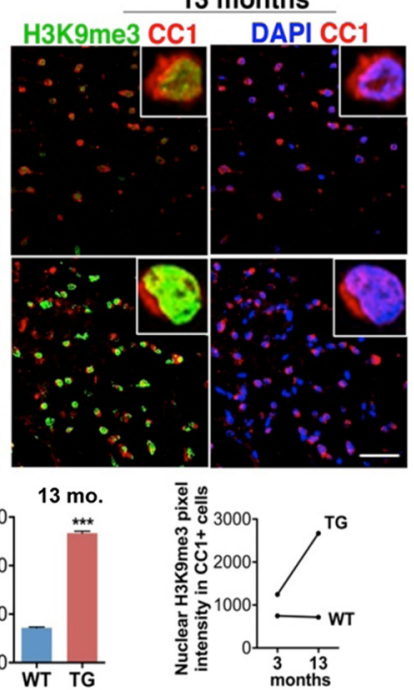

3 months
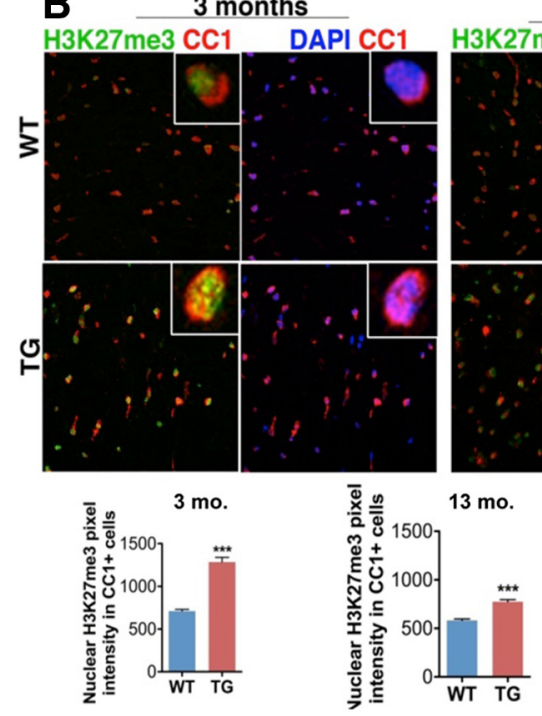

D
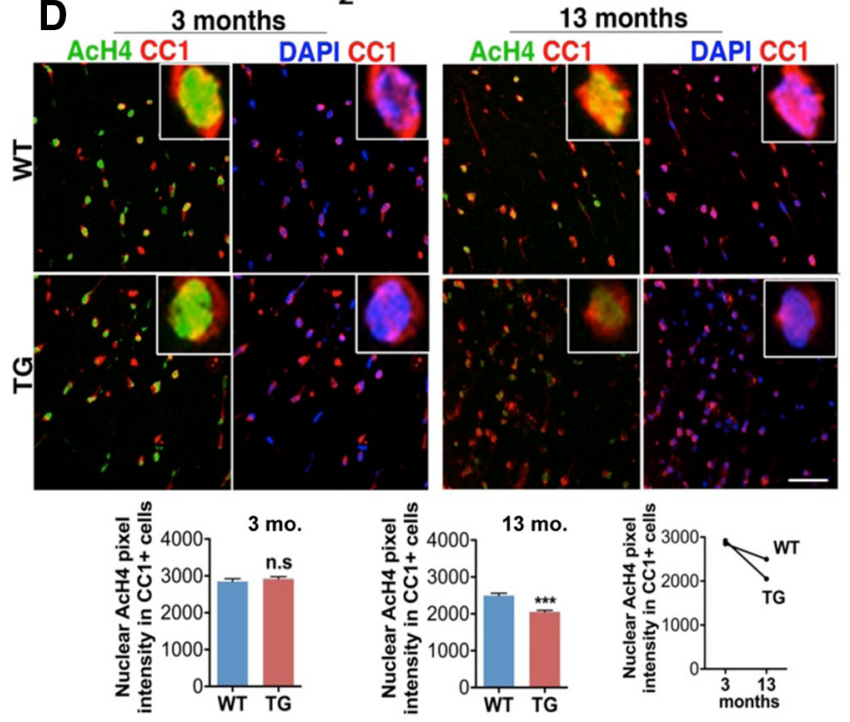

Figure 5. Altered age-dependent oligodendrocyte-specific chromatin modifications in PIp-FLAG-LMNB1 TG mice. A-D, Confocal images of spinal cord sections from WT and TG mice at 3 months $(3 \mathrm{mo})$ and 13 months $(13 \mathrm{mo})$ stained with antibodies against different histone modifications in oligodendrocytes. In all cases, the histone antibodies are in green, the oligodendrocyte marker C 1 in red, and DAPI in blue. For each figure, bottom shows a quantitative plot of the immunoreactivity at different time points (data plotted are mean \pm SEM). H3K9me3 staining ( $\boldsymbol{A})$ and HeK27me3 staining $(\boldsymbol{B})$. Note that both these repressive marks show significant increases in TG samples at both the 13 and 3 month time points relative to WT. AcH3 staining ( $\boldsymbol{C}$ ) and AcH4 staining $(\boldsymbol{D})$. Note that both these activating histone marks show a reduction in TG samples relative to WT at the 13 month time point. For all graphs $n=3-4$ animals per genotype at each time point. Data plotted are mean \pm SEM; ${ }^{* * *} p<0.001$.

synthesis, and SREBP2 regulates cholesterol synthesis and uptake (Shao and Espenshade, 2012). The Srebf are known to play important roles in both central and peripheral myelination (Lebrun-Julien et al., 2014; Norrmén et al., 2014). All the lipid synthesis genes that we found to be consistently downregulated, with the exception of Elovl7, are previously known targets of SREBP 1 and 2 (Horton et al., 2003). We therefore sought to determine whether these transcription factor genes showed expression changes in the TG mice. QT-PCR analysis revealed a small but significant reduction in Srebfla levels at 3 months, whereas Srebf1c showed significant reductions at 3 and 8 months in TG animals. Srebf2 expression showed the most dramatic agedependent decline in TG animals and was significantly reduced at the 8 and 13 month time points (Fig. 8D). Consistent with these results, the RNA-Seq data showed a significant reduction in Srebf2 expression at 13 months.
PLP-FLAG-LMNB1 mice show an age-dependent reduction in myelin-enriched lipid species

Lipids make up $70 \%$ of the dry weight of myelin and a disruption of lipid synthesis has been shown to cause both central and peripheral demyelination (Chrast et al., 2011). To determine whether the Plp-FLAG-LMNB1 mice showed a reduction in myelin-enriched lipids as predicted from our gene expression data, we performed a comparative lipidomic analysis of spinal cord tissue from TG and WT mice. As with the previous analyses, we chose 3 and 13 month time points to be able to identify lipid changes before the phenotype that might be causative rather than secondary to the demyelination. Quantitative liquid chromatography mass spectroscopy (LC-MS) revealed a significant reduction in total cholesterol at both time points, whereas total phospholipid levels were significantly reduced only at the 13 month time point (Fig. 9A,B). A detailed analysis of individual 
A

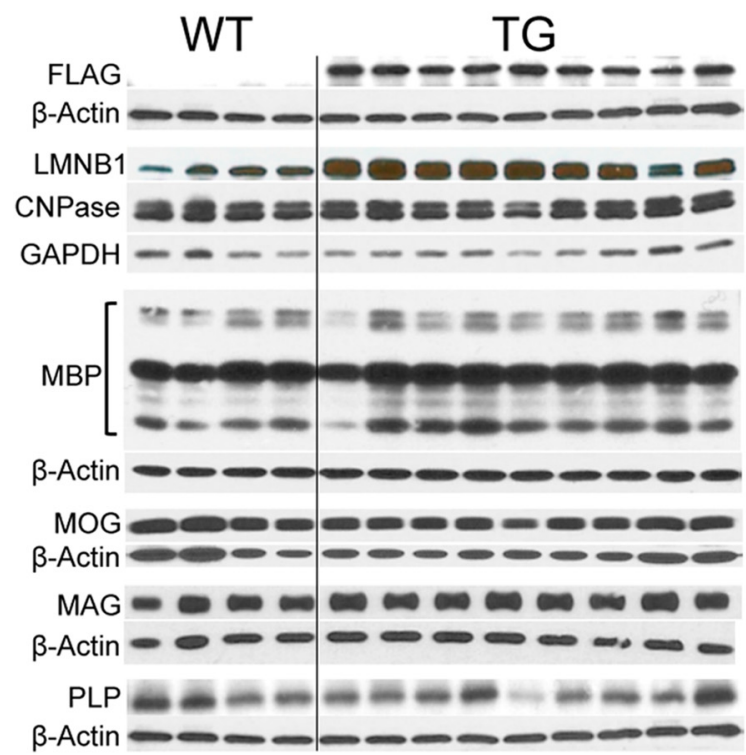

B
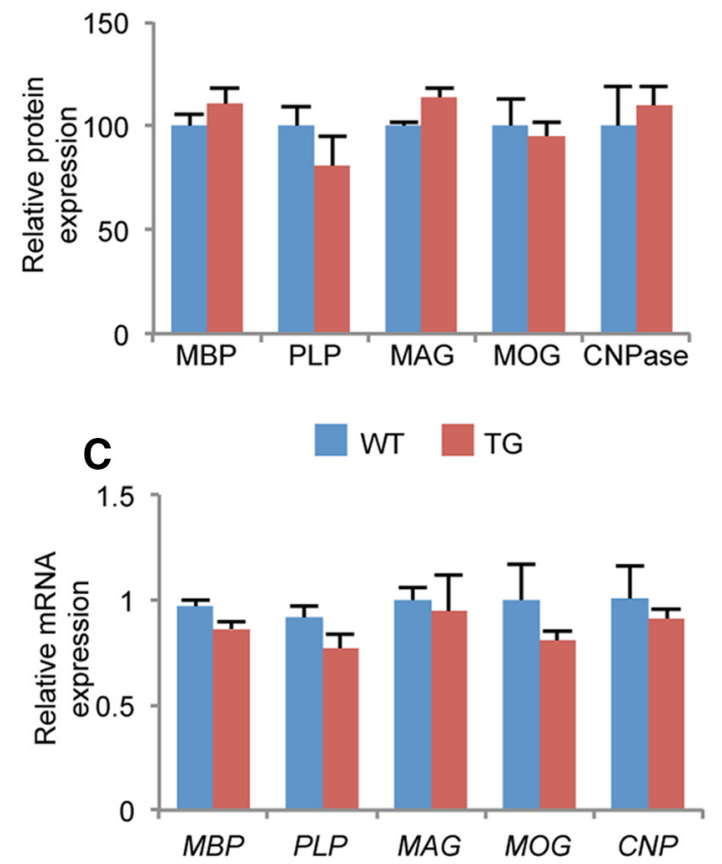

Figure 6. PIp-FLAG-LMNB1 TG mice do not show significant alterations of myelin-specific proteins. $A$, Immunoblots of spinal cord protein lysates from 13 month WT and TG animals probed with antibodies against the myelin-specific proteins CNPase, MBP, MOG, MAG, and PLP1. B, Quantitation of immunoblot from $A$ show no significant differences in the levels of these proteins between WT and TG samples. Data plotted are mean band intensities \pm SEM, first normalized to loading control and then to WT samples ( $n=8$ for TG; $n=4$ for WT). $C$, Quantitation of real time PCR analysis of the expression levels of these genes also shows no significant differences between TG and WT samples. Data plotted are mean expression levels \pm SEM, first normalized to internal control and then to WT samples ( $n=3-4$ animals for each genotype).

phospholipid (PL) classes revealed a significant reduction of phosphatidylethanolamine (PE), phosphatidylcholine (PC), phosphatidylserine (PS), and sphingomyelin (SM) in the 13 month TG samples (Fig. 9C). We were also able to identify significant reductions in individual molecular species in the PE, PC, PS, and SM classes (Fig. 9D). A closer examination revealed that many of the individual molecular species significantly reduced in the TG animals were those that have been previously shown to be enriched in myelin (18:1, 20:0, 22:0, and 24:1; Chrast et al., 2011). Although we did not observe a reduction in total PL or individual PL classes at 3 months (data not shown), a few individual species of PE, PC, and PS were significantly reduced even at this time point (Fig. 9D).

To confirm that the lipid changes we observed were specific to the white matter regions of the spinal cord, we used a recently developed technique: MALDI-MS imaging. MALDI-MS imaging allows for the precise spatial localization and distribution of individual molecular species enabling the "biochemical microscopy" of lipids in the CNS (Amoscato et al., 2014). We were able to identify specific PE and PC species that showed robust differences between white and gray matter using MALDI-MS imaging of 3 month spinal cord sections (Fig. 10A). As predicted, multiple species that showed significant differences between TG and WT samples using LC-MS were enriched in the white matter of the spinal cord. Although semiquantitative, we were able to detect subtle reductions in amounts of PE (p16:0/18:1, p18:0/18:1, 18: 0/18:1) and PC (18:1/20:0, 18:0/20:1, 16:0/18:1) species using MALDI imaging in the 3 month spinal cord sections. However, averaging out all PE and PC species diminished differences between TG and WT samples at this time point, consistent with the LC-MS data. PC 16:0/16:0 was the only PC species to localize predominantly in the gray matter region and interestingly we were able to observe reductions of this species specifically in the white matter of the TG sections compared with WT. Because MALDI-MS imaging detects region-specific differences and is not subjected to signal averaging over an entire tissue slice extract, these spatial differences, which would not be picked up by LC-MS, now became apparent in the white matter region.

These results confirm that the Plp-FLAG-LMNB1 TG mice do indeed show an age-dependent reduction in myelin-enriched lipid levels, most likely caused by a downregulation of lipid synthesis gene expression.

\section{Discussion}

Our results have identified, for the first time, significant lipid dysregulation in the transgenic mice that overexpress LMNB1 in oligodendrocytes. We hypothesize that this dysregulation may play a critical role in the demyelination phenotype and secondary pathological events that ultimately result in premature mortality (Fig. 10B).

The age-dependent motor dysfunction we have described is consistent with a recent publication that used mice derived from the oligodendrocyte-specific lamin B1 expression construct (Heng et al., 2013). However, this previous report did not analyze the spinal cord for pathology and concluded that myelin alterations in the brainstem, analyzed only by EM, were responsible for the phenotype. The demyelination we have described in our current study is significantly milder in the brainstem compared with the spinal cord (Fig. 2). Furthermore, the report by Heng et al., 2013, did not observe any microglial or astroglial infiltration in the brainstem and did not test for neuronal loss or axonal damage. Given the severity of the pathological alterations described in this report, and the importance of these cell types in the pathology, it would seem more likely that the spinal cord injury is the 
A

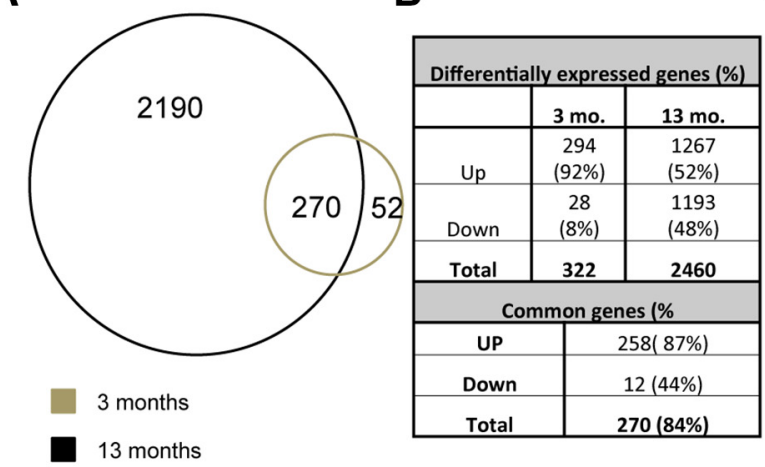

D

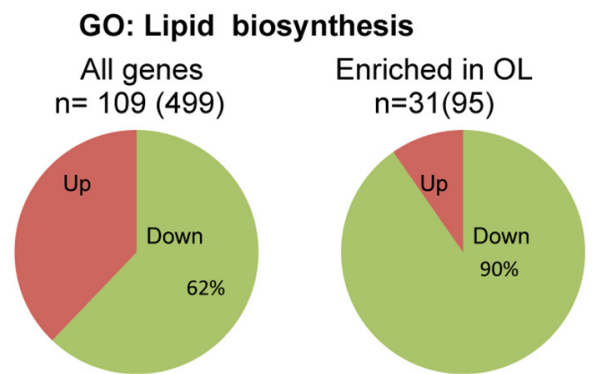

C

\begin{tabular}{|c|c|c|c|c|}
\hline \multirow[t]{2}{*}{$\begin{array}{c}\text { Gene } \\
\text { Symbol }\end{array}$} & \multirow[t]{2}{*}{ Full name } & \multicolumn{2}{|c|}{$\begin{array}{c}\text { Fold change relative } \\
\text { to wild type }\end{array}$} & \multirow{2}{*}{$\begin{array}{c}\text { Enriched in } \\
\text { myelinating } \\
\text { oligos. }\end{array}$} \\
\hline & & $3 \mathrm{mo}$. & $13 \mathrm{mo}$. & \\
\hline Ldlr & Low-Density Lipoprotein (LDL) Receptor & 0.71 & 0.31 & Yes \\
\hline Cyp51 & Lanosterol 14-demethylase (CYP51) & 0.75 & 0.37 & Yes \\
\hline Hmgcs1 & 3-Hydroxy-3-Methylglutaryl-CoA Synthase 1 & 0.65 & 0.38 & Yes \\
\hline Sqle & Squalene Epoxidase & 0.75 & 0.41 & No \\
\hline Sc4mol & Methylsterol Monooxygenase & 0.71 & 0.41 & Yes \\
\hline Hmger & 3-Hydroxy-3-Methylglutaryl-CoA Reductase & 0.74 & 0.55 & Yes \\
\hline Scd1 & Stearoyl-CoA desaturase-1 & 0.62 & 0.55 & Yes \\
\hline Dher7 & DHCR7 7-dehydrocholesterol reductase & 0.73 & 0.58 & Yes \\
\hline Elovi7 & ELOVL Fatty Acid Elongase & 0.74 & 0.69 & Yes \\
\hline ApoE & Apolipoprotein E & 2.2 & 8.8 & No \\
\hline
\end{tabular}

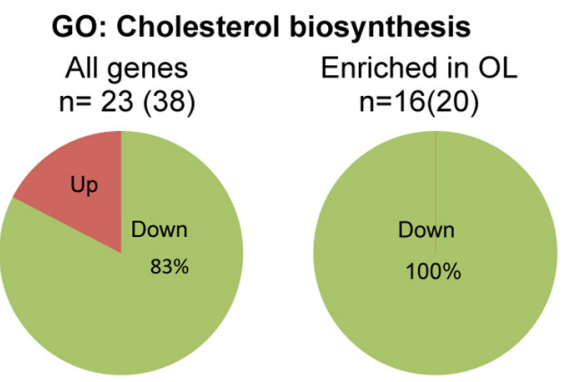

Figure 7. Transcriptomic analysis reveals downregulation of lipid-synthesis gene expression in PIp-FLAG-LMNB1 TG mice. $A, B$, RNA-Seq analysis of spinal cords from TG mice revealed a significant overlap of genes that were differentially expressed relative to WT at 3 months $(3 \mathrm{mo})$ and 13 months ( $13 \mathrm{mo})$. C, Nine of the 12 genes that were downregulated and common between the 3 and 13 month time points (green) were involved in lipid synthesis. Expression of the ApoE gene (red) is significantly upregulated at both time points. D, Genes differentially expressed at 13 months are involved in $\mathrm{GO}$ pathways of lipid (left) and cholesterol (right) biosynthesis. Pie charts show percentage of genes that were upregulated and downregulated. For each pathway, pie charts to the right show the subset of these genes that were highly expressed in myelinating oligodendrocytes ( $0 \mathrm{~L}$ ). In all cases, $n$ represents the number of genes differentially expressed at the 13 month time point and numbers in parenthesis represent the total number of genes in each of these pathways.

cause of the motor phenotype and reduced survival of the transgenic mice overexpressing lamin B1 in oligodendrocytes. Heng et al., 2013 also showed a dramatic reduction in the major myelin protein, PLP1, in transgenic mice, a finding that we were unable to replicate (Fig. 6). The deficiency of PLP1 alone in mice does not interfere with myelination nor does it cause premature mortality as PLP1-null mice only show mild impairment of motor functions at 16 months of age (Klugmann et al., 1997; Griffiths et al., 1998). These observations are inconsistent with the phenotype exhibited by the lamin B1 overexpressing transgenic mice and suggest that additional pathways, such as the one that we have described involving oligodendrocyte lipid metabolism, may underlie the pathology.

The TG mice share many histopathological and biochemical features with other demyelinating mouse models caused by lipid defects. The vacuolar pattern of white matter degeneration observed in the TG mice has also been observed in mice with disrupted synthesis of myelin-associated lipids such as galactocerebrosides or gangliosides (Coetzee et al., 1996, 1999; Yamashita et al., 2005). Mice null for PGC- $1 \alpha$, a gene that plays an important role in cholesterol biosynthesis and postnatal myelinogenesis, also showed a vacuolar degenerative white matter phenotype (Lin et al., 2004).

The demyelination in the Plp-FLAG-LMNB1 mice was not accompanied by significant reductions in expression of the major myelin proteins (Fig. 6). Similar findings have also been observed in mice that manifested myelin defects due to the lack of galactocerebrosides or gangliosides (Coetzee et al., 1998, 1999; Yamashita et al., 2005). Compared with minor alterations in the levels of the major myelin proteins in the TG mice, we observed dramatic age-dependent reductions in the expression of multiple genes responsible for lipid synthesis, which are important for myelin formation. All but one of the lipid synthesis genes that were consistently downregulated (Fig. 7C) have been previously reported to be enriched in myelinating oligodendrocytes (Cahoy et al., 2008). These results, together with the fact that we see a reduction of myelin-enriched lipids even before the onset of demyelination, strongly suggest that lipid defects may play a role in the pathogenic mechanisms that underlie the ADLD mouse model.

Similar to our TG animals, mice with oligodendrocytespecific disruptions of cholesterol synthesis pathways showed increased levels of the cholesterol transport protein, ApoE and demyelination most severely affecting the spinal cord (Saher et al., 2005). Another link to cholesterol dysregulation in our mouse model was the expression pattern of Srebf2. This transcription factor showed a much greater age-dependent decline compared with Srebf1a or 1c. Given the role of SREBP2, specifically in cholesterol metabolism, it might explain our results showing that a much higher percentage of genes involved in cholesterol synthesis were preferentially downregulated at 13 months (Fig. 7D).

Mutations in Lamin A/C have previously been linked to a class of disorders, the lipodystrophies, that are characterized by the selective loss of adipose tissue (Bidault et al., 2011). The nuclear lamina thus appears to have a distinct role in the regulation of lipid metabolism, though the precise mechanisms are yet to be identified. Oligodendrocyte membranes are highly enriched in lipids (Bradl and Lassmann, 2010; Chrast et al., 2011). It would 

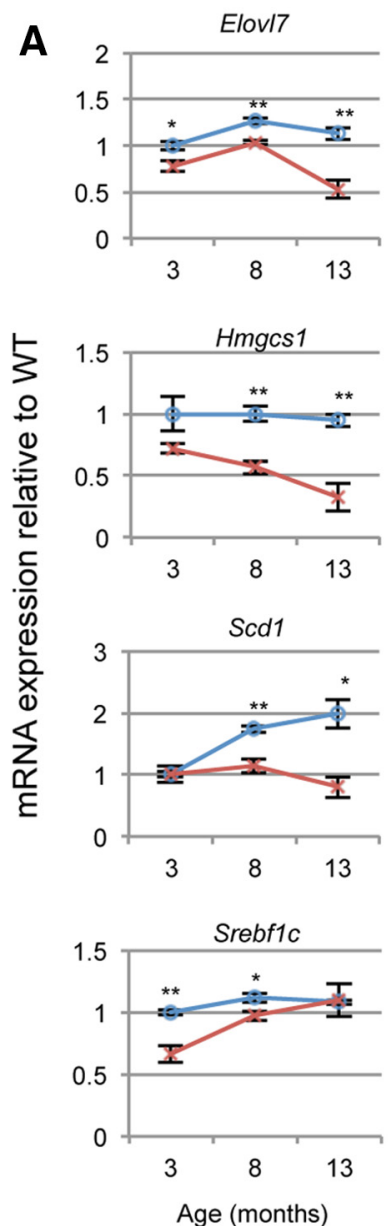

WT
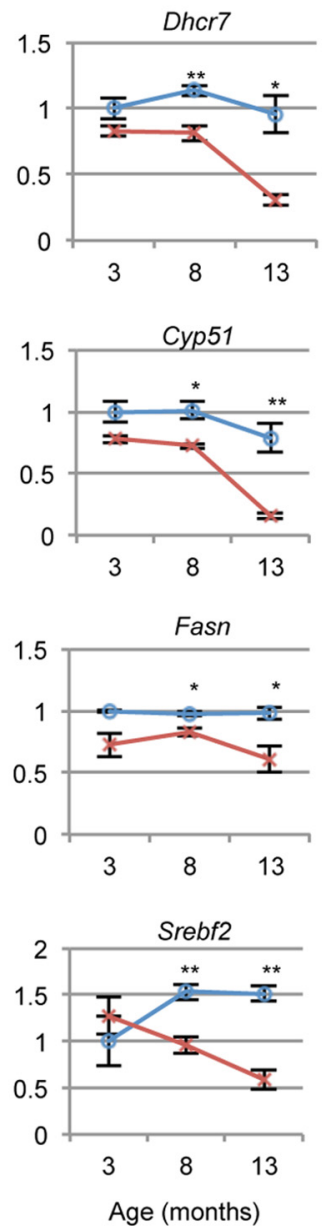

Age (months)
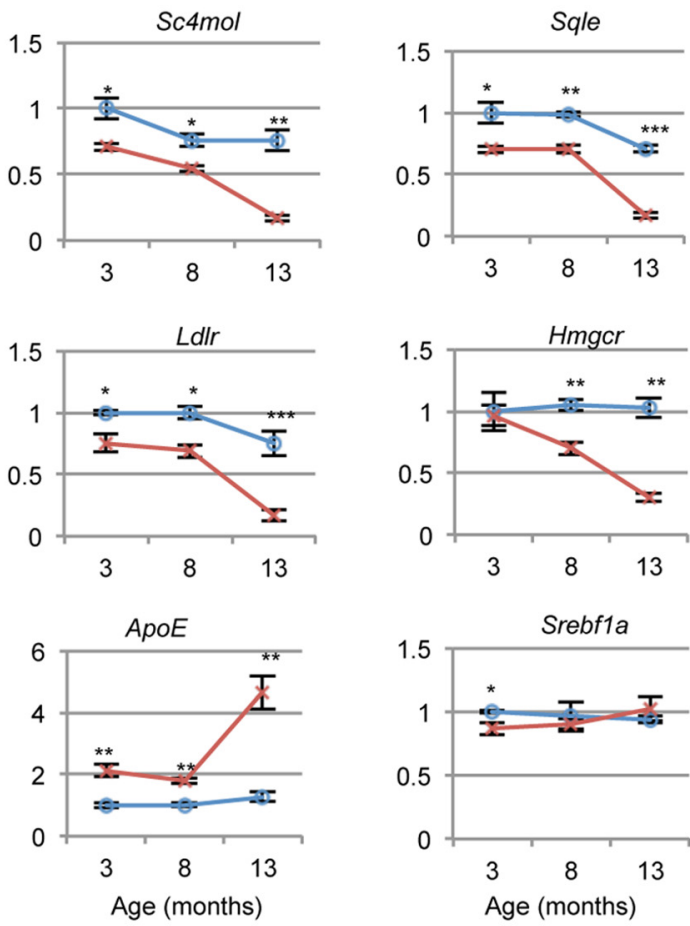

B

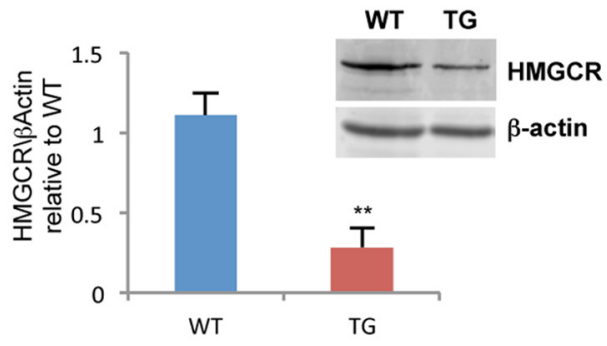

C

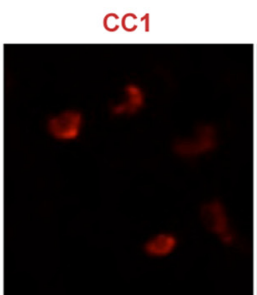

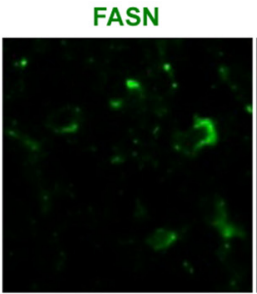

WT

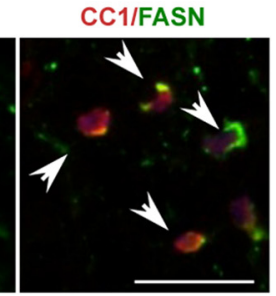

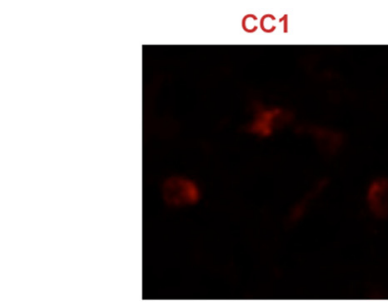
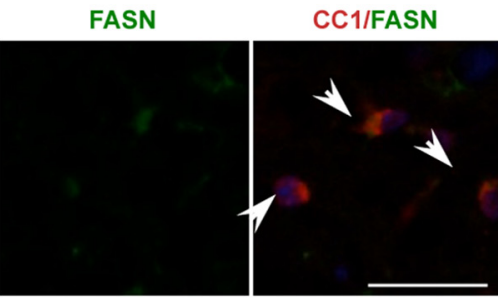

TG

Figure 8. Age-dependent reduction of lipid gene expression in PIp-FLAG-LMNB1 TG mice. A, QT-PCR validation of RNA-Seq data showed that all nine lipid synthesis genes common between 3 and 13 month time points were consistently downregulated in TG samples and showed significant age-dependent decline comparative to age matched WT controls. Expression levels of ApoE and Fasn are also shown. In addition, Srebf2 showed significant age-dependent reductions in expression in TG samples, whereas Srebf1a and 1 c show reduction in expression only at earlier time points. Expression levels of TG samples are first normalized to internal control and then to WT controls for each time point. Data plotted are mean \pm SEM; ${ }^{*}<0.05{ }^{* *} p<0.01,{ }^{* * *} p<0.001 ; n=3-4$ animals per genotype for each time point. $\boldsymbol{B}$, Protein levels of HMGCR are significantly reduced in 13 month TG spinal cords, data plotted are mean \pm SEM; ${ }^{* *} p<0.01 ; n=3$. $\boldsymbol{C}, 0$ ligodendrocytespecific reductions of FASN expression in 13 month TG spinal cord sections. Arrows point to oligodendrocytes stained with antibodies against CC1 and FASN. Scale bar, $25 \mu \mathrm{m}$.

therefore be logical to hypothesize that perturbations of the nuclear lamina in the CNS would most severely affect the cell types that have active lipid metabolic pathways, such as oligodendrocytes. Other neurological diseases, such as spinal muscular atrophy, are caused by mutations in genes that are ubiquitously expressed, however, it in unclear why these mutations have neuron-specific effects (Edens et al., 2015), Our findings of lipid dysregulation provide a rationale as to why increased LMNB1, a protein that is also widely expressed in different cell types, specifically targets oligodendrocytes and causes a white matter defect, such as ADLD.

Our results might also provide clues for the age dependence of the degenerative phenotypes in both mice and humans. We show that, with advancing age, oligodendrocytes in the Plp-FLAG- 
A

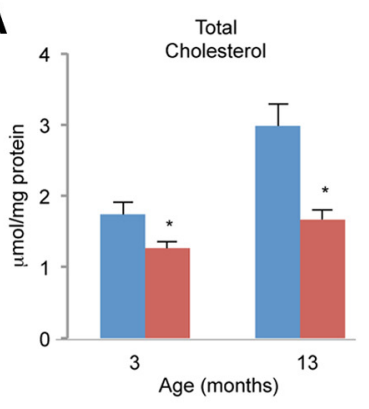

D

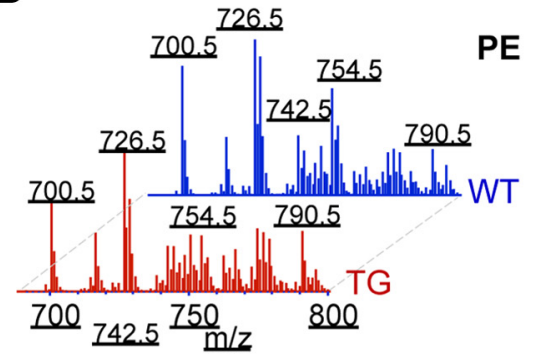

B
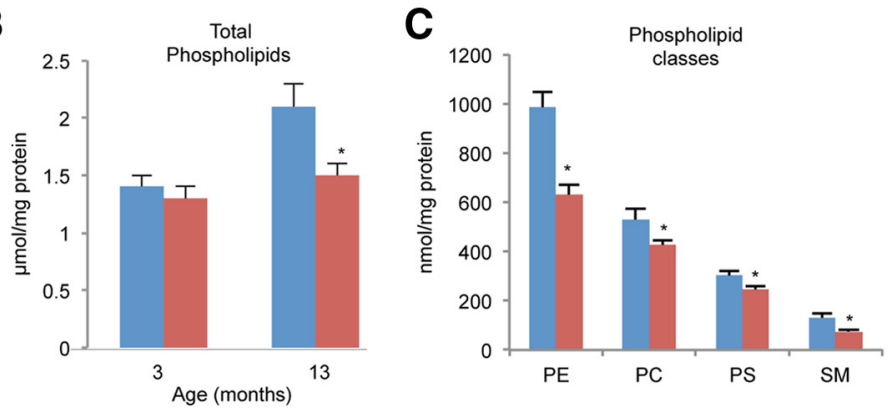

WT

TG

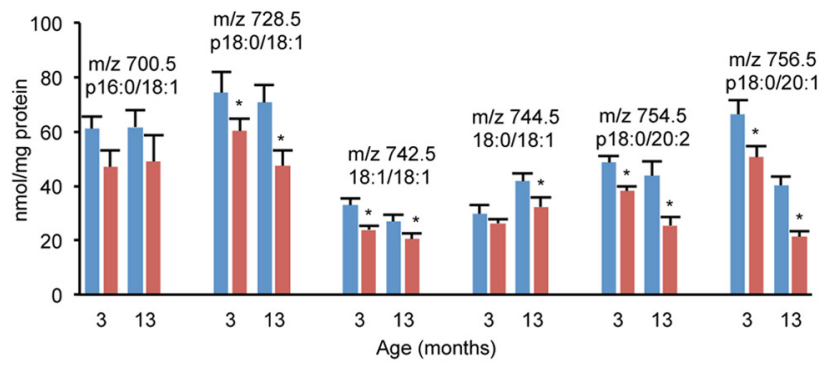

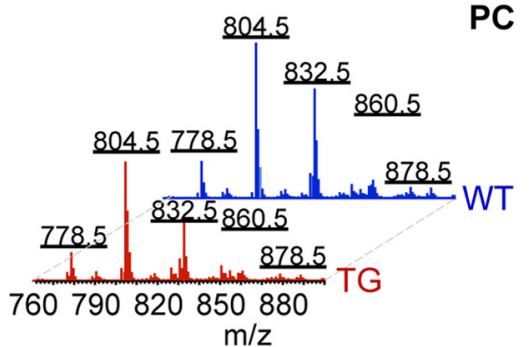
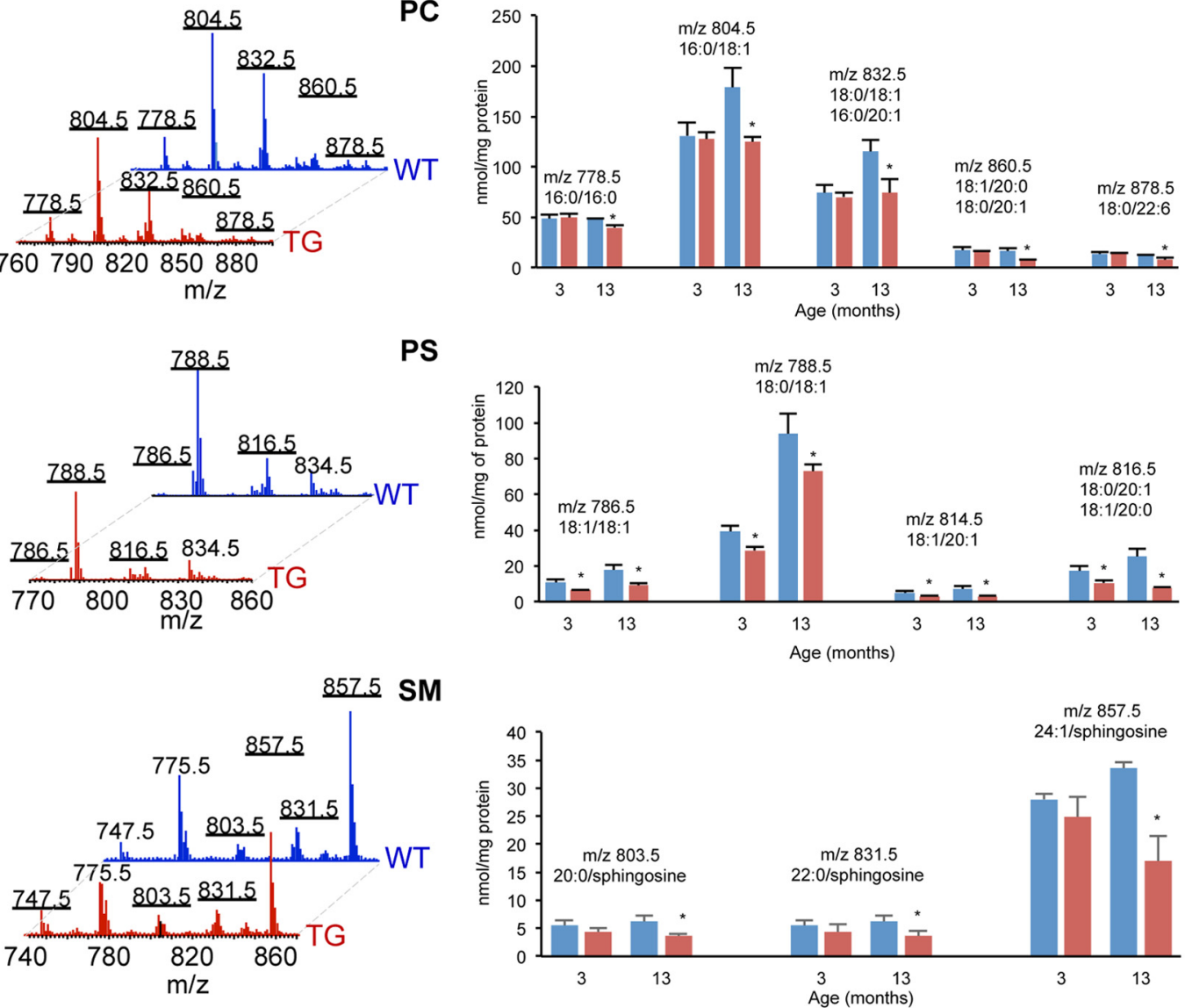

Figure 9. Lipidomic analysis of PIp-FLAG-LMNB1 TG mice spinal cord. A, Quantitation of total cholesterol content in spinal cord extracts showed significant reduction in TG samples at 3 and 13 month time points compared with WT. Data plotted are mean $\pm \mathrm{SEM} ;{ }^{*} p<0.05 ; n=4$ animals for each genotype. $\boldsymbol{B}$, Quantitation of total PL content in spinal cord extracts showed significant reduction in TG samples at the 13 month time point. Data plotted are mean \pm SD; ${ }^{*} p<0.05, n=3$ animals for each genotype. $C$, Quantitation of Individual PL classes in 13 month spinal cord extracts. TG samples showed significant reduction of different PL classes: PE, PC, PS, and SM. Data plotted are mean \pm SD; ${ }^{*} p<0.05, n=3$ animals for each genotype. $D$, Representative MS spectra of PE, PC, PS, and SM obtained from spinal cords of 13-month-old WT and TG mice (left). Numbers above peaks represent the mass/charge (m/z) ratio, which identifies individual molecular species. Right, Quantitative assessment of these individual molecular species from 3 and 13-month-old TG and WT animals. Each molecular species is represented by the m/z ratio and the corresponding length of the fatty acid side chain. PC and SM were detected as adducts with acetic and formic acid. p- $s n-1$ vinyl ether (alkenyl- or plasmalogen) linkage. Data plotted are mean \pm SD; ${ }^{*}<0.05$, $n=3$ for per genotype for each time point. 
A

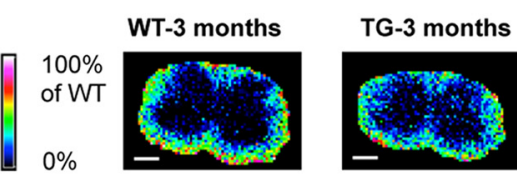

PE(p16:0/18:1)

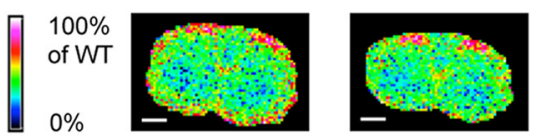

$\operatorname{PE}(\mathrm{p} 18: 0 / 18: 1)$

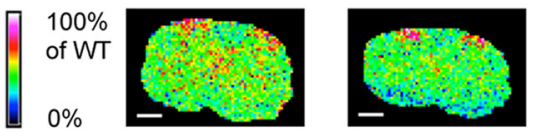

$\operatorname{PE}(18: 0 / 18: 1)$

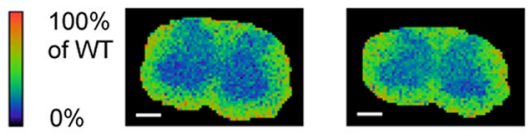

ALLPE

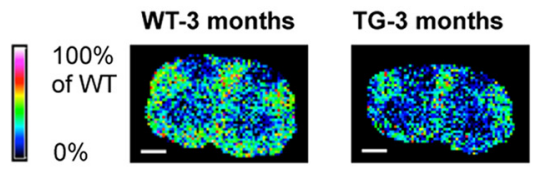

PC(18:1/20:0), (18:0/20:1)

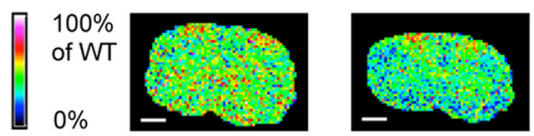

$\mathrm{PC}(16: 0 / 18: 1)$

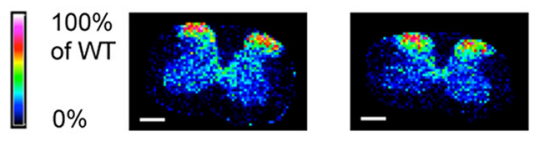

$\mathrm{PC}(16: 0 / 16: 0)$

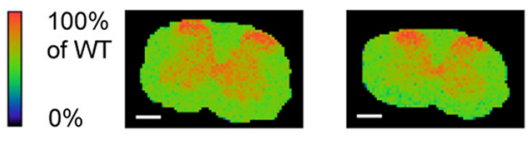

ALL PC

B

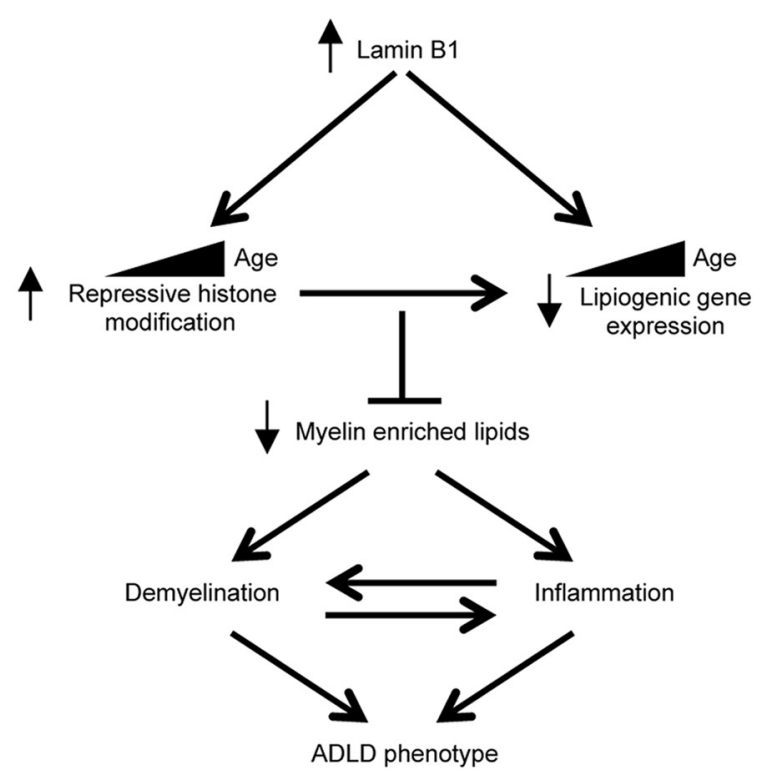

Figure 10. MALDI imaging of spinal cord and model for disease mechanism in PIp-FLAG-LMNB1 TG mice. A, MALDI lipid imaging of spinal cord sections from 3-month-old TG and WT mice for individual PE and PC molecular species (listed below each image). Images are pseudocolored and the TG intensities have been normalized to maximal WT intensity to allow direct comparison across TG and WT images. Intensities of these lipid species showed reduction in white matter regions of TG spinal cord. For PE images, p16:0/18:1 and p18:0/18:1 refer to the plasmalogen type of fatty acid side chains. In the case of PC (18:1/20:0), (18:0/20:1), both these species are isobaric and cannot be differentiated by MALDI imaging. Scale bar, $500 \mu \mathrm{m}$. $\boldsymbol{B}$, Mechanistic model linking lamin B1 overexpression, chromatin modification, lipid synthesis, and demyelination. This model provides a rationale for the age dependence and white matter involvement in ADLD.

LMNB1 mice exhibit a shift in histone marks toward a more repressive transcriptional state. These observations are consistent with previous reports linking the nuclear lamina to aging and chromatin regulation: chromatin associated with the nuclear lamina is characterized by repressive histone marks and transcriptionally silenced genes (Guelen et al., 2008). The nuclear lamina has also been shown to exhibit age-dependent structural alterations (Haithcock et al., 2005). Furthermore, epigenetic changes have also been shown to underlie the agedependent decline in remyelination efficiency (Shen et al.,

2008). Thus, our findings suggest a chromatin-mediated mechanism whereby the nuclear lamina downregulates the expression of genes involved in lipid synthesis in an age-dependent manner that can potentially explain the late onset of the mouse phenotype.

Lamin B1 may directly downregulate the expression of individual lipid synthesis genes by altering their chromatin to a more repressive state or may also act indirectly through the SREBP transcription factors. In addition to the transcriptional regulation of the Srebf genes, posttranslational mechanisms may also link the LMNB1 and the SREBP proteins. Previous studies have reported that lamin A overexpression results in the sequestration of SREBP1 at the nuclear periphery, thus decreasing the pool of active proteins in the nucleoplasm (Duband-Goulet et al., 2011). Although neither of these pathways is mutually exclusive, further studies are required to determine the exact nature of their role in lamin B1-mediated lipid dysregulation.

Our results suggest that an inhibition of lipid synthesis in oligodendrocytes results in demyelination and that an inflammatory response involving astrocytes and microglia may further exacerbate the injury to the myelin sheath ultimately leading to axonal damage and neuronal cell death. Whether the inflammatory response is triggered primarily by the lipid dysregulation or is mediated by an independent pathway caused by LMNB1 overexpression in oligodendrocytes is yet to be determined. Altered LMNB1 expression has been associated with increased levels of reactive oxygen species and this may be a potential pathway that triggers an inflammatory response independent of lipid dysregulation (Malhas et al., 2009; Shimi et al., 2011; Barascu et al., 2012; Hutchison, 2012).

The results from our mouse model mirror a number of findings in ADLD and provide insights into the human disease. In ADLD, early demyelination is usually observed in the brainstem and the spinal cord (Melberg et al., 2006; Sundblom et al., 2009). Although we have observed an extremely mild pathology in the brainstem, the vacuolar demyelination we have detected in the spinal cord is similar to that described in ADLD (Melberg et al., 2006). In addition, we did not observe a reduction in oligodendrocyte number, another pathological hallmark of ADLD (Coffeen et al., 2000; Melberg et al., 2006). This suggests that LMNB1-induced premature oligodendrocyte death is not the cause of the demyelination phenotype. Thus, although the pathological mechanisms of the phenotypes caused by lamin B1 overexpression in the mouse and human are likely to be the same, the exact location of the pathol- 
ogy may differ. Increased involvement of the spinal cord may be a consequence of the fact that the exogenous lamin B1 is maximally expressed in this region of the CNS. However, it may also indicate that oligodendrocytes in the spinal cord are uniquely susceptible to the effect of lamin B1 overexpression.

In conclusion, we have identified a novel link between the nuclear lamina, chromatin modification and lipid metabolism in myelinating oligodendrocytes that provide a framework to explain the age dependence and white matter involvement of the disease phenotype. Although our results suggest that a downregulation of lipid synthesis pathways may be a potential pathological mechanism in the ADLD mouse model, further experiments are required to confirm this hypothesis. These results not only have implications for disease pathogenesis but may also shed light on the regulation of lipid pathways in the complex programs of myelin turnover and maintenance.

\section{Notes}

Supplemental material for this article is available at https://helpdesk. hgen.pitt.edu/downloads/Primer_List.pdf. A list of primers used in the study. This material has not been peer reviewed.

\section{References}

Amoscato AA, Sparvero LJ, He RR, Watkins S, Bayir H, Kagan VE (2014) Imaging mass spectrometry of diversified cardiolipin molecular species in the brain. Anal Chem 86:6587-6595. CrossRef Medline

Anders S, Huber W (2010) Differential expression analysis for sequence count data. Genome Biol 11:R106. CrossRef Medline

Barascu A, Le Chalony C, Pennarun G, Genet D, Imam N, Lopez B, Bertrand $P$ (2012) Oxidative stress induces an ATM-independent senescence pathway through p38 MAPK-mediated lamin B1 accumulation. EMBO J 31:1080-1094. CrossRef Medline

Bartoletti-Stella A, Gasparini L, Giacomini C, Corrado P, Terlizzi R, Giorgio E, Magini P, Seri M, Baruzzi A, Parchi P, Brusco A, Cortelli P, Capellari S (2015) Messenger RNA processing is altered in autosomal dominant leukodystrophydagger. Hum Mol Genet 24:2746-2756. CrossRef Medline

Bidault G, Vatier C, Capeau J, Vigouroux C, Béréziat V (2011) LMNAlinked lipodystrophies: from altered fat distribution to cellular alterations. Biochem Soc Trans 39:1752-1757. CrossRef Medline

Bradl M, Lassmann H (2010) Oligodendrocytes: biology and pathology. Acta Neuropathologica 119:37-53. CrossRef Medline

Butin-Israeli V, Adam SA, Goldman AE, Goldman RD (2012) Nuclear lamin functions and disease. Trends Genet 28:464-471. CrossRef Medline

Cahoy JD, Emery B, Kaushal A, Foo LC, Zamanian JL, Christopherson KS, Xing Y, Lubischer JL, Krieg PA, Krupenko SA, Thompson WJ, Barres BA (2008) A transcriptome database for astrocytes, neurons, and oligodendrocytes: a new resource for understanding brain development and function. J Neurosci 28:264-278. CrossRef Medline

Chrast R, Saher G, Nave KA, Verheijen MH (2011) Lipid metabolism in myelinating glial cells: lessons from human inherited disorders and mouse models. J Lipid Res 52:419-434. CrossRef Medline

Coetzee T, Fujita N, Dupree J, Shi R, Blight A, Suzuki K, Suzuki K, Popko B (1996) Myelination in the absence of galactocerebroside and sulfatide: normal structure with abnormal function and regional instability. Cell 86:209-219. CrossRef Medline

Coetzee T, Dupree JL, Popko B (1998) Demyelination and altered expression of myelin-associated glycoprotein isoforms in the central nervous system of galactolipid-deficient mice. J Neurosci Res 54:613-622. CrossRef Medline

Coetzee T, Suzuki K, Nave KA, Popko B (1999) Myelination in the absence of galactolipids and proteolipid proteins. Mol Cell Neurosci 14:41-51. CrossRef Medline

Coffeen CM, McKenna CE, Koeppen AH, Plaster NM, Maragakis N, Mihalopoulos J, Schwankhaus JD, Flanigan KM, Gregg RG, Ptácek LJ, Fu YH (2000) Genetic localization of an autosomal dominant leukodystrophy mimicking chronic progressive multiple sclerosis to chromosome $5 \mathrm{q} 31$. Hum Mol Genet 9:787-793. CrossRef Medline

Duband-Goulet I, Woerner S, Gasparini S, Attanda W, Kondé E, TellierLebègue C, Craescu CT, Gombault A, Roussel P, Vadrot N, Vicart P,
Ostlund C, Worman HJ, Zinn-Justin S, Buendia B (2011) Subcellular localization of SREBP1 depends on its interaction with the C-terminal region of wild-type and disease related A-type lamins. Exp Cell Res 317: 2800-2813. CrossRef Medline

Dupree JL, Suzuki K, Popko B (1998) Galactolipids in the formation and function of the myelin sheath. Microsc Res Tech 41:431-440. CrossRef Medline

Dupree JL, Polak PE, Hensley K, Pelligrino D, Feinstein DL (2015) Lanthionine ketimine ester provides benefit in a mouse model of multiple sclerosis. J Neurochem 134:302-314. CrossRef Medline

Edens BM, Ajroud-Driss S, Ma L, Ma YC (2015) Molecular mechanisms and animal models of spinal muscular atrophy. Biochimica et biophysica acta 1852:685-692. CrossRef Medline

Ferrera D, Canale C, Marotta R, Mazzaro N, Gritti M, Mazzanti M, Capellari S, Cortelli P, Gasparini L (2014) Lamin B1 overexpression increases nuclear rigidity in autosomal dominant leukodystrophy fibroblasts. FASEB J 28:3906-3918. CrossRef Medline

Folch J, Lees M, Sloane Stanley GH (1957) A simple method for the isolation and purification of total lipides from animal tissues. J Biol Chem 226:497509. Medline

Fuss B, Mallon B, Phan T, Ohlemeyer C, Kirchhoff F, Nishiyama A, Macklin WB (2000) Purification and analysis of in vivo-differentiated oligodendrocytes expressing the green fluorescent protein. Dev Biol 218:259-274. CrossRef Medline

Gerace L, Huber MD (2012) Nuclear lamina at the crossroads of the cytoplasm and nucleus. J Struct Biol 177:24-31. CrossRef Medline

Ghosh S, Zhou Z (2014) Genetics of aging, progeria and lamin disorders. Curr Opin Genet Dev 26:41-46. CrossRef Medline

Goldman RD, Gruenbaum Y, Moir RD, Shumaker DK, Spann TP (2002) Nuclear lamins: building blocks of nuclear architecture. Genes Dev 16: 533-547. CrossRef Medline

Griffiths I, Klugmann M, Anderson T, Yool D, Thomson C, Schwab MH, Schneider A, Zimmermann F, McCulloch M, Nadon N, Nave KA (1998) Axonal swellings and degeneration in mice lacking the major proteolipid of myelin. Science 280:1610-1613. CrossRef Medline

Guelen L, Pagie L, Brasset E, Meuleman W, Faza MB, Talhout W, Eussen BH, de Klein A, Wessels L, de Laat W, van Steensel B (2008) Domain organization of human chromosomes revealed by mapping of nuclear lamina interactions. Nature 453:948-951. CrossRef Medline

Haithcock E, Dayani Y, Neufeld E, Zahand AJ, Feinstein N, Mattout A, Gruenbaum Y, Liu J (2005) Age-related changes of nuclear architecture in Caenorhabditis elegans. Proc Natl Acad Sci U S A 102:16690-16695. CrossRef Medline

Heng MY, Lin ST, Verret L, Huang Y, Kamiya S, Padiath QS, Tong Y, Palop JJ, Huang EJ, Ptáček LJ, Fu YH (2013) Lamin B1 mediates cellautonomous neuropathology in a leukodystrophy mouse model. J Clin Invest 123:2719-2729. CrossRef Medline

Horton JD, Shah NA, Warrington JA, Anderson NN, Park SW, Brown MS, Goldstein JL (2003) Combined analysis of oligonucleotide microarray data from transgenic and knockout mice identifies direct SREBP target genes. Proc Natl Acad Sci U S A 100:12027-12032. CrossRef Medline

Hutchison CJ (2012) B-type lamins and their elusive roles in metazoan cell proliferation and senescence. EMBO J 31:1058-1059. CrossRef Medline

Jung HJ, Lee JM, Yang SH, Young SG, Fong LG (2013) Nuclear lamins in the brain- new insights into function and regulation. Mol Neurobiol 47:290 301. CrossRef Medline

Kim D, Pertea G, Trapnell C, Pimentel H, Kelley R, Salzberg SL (2013) TopHat2: accurate alignment of transcriptomes in the presence of insertions, deletions and gene fusions. Genome Biol 14:R36. CrossRef Medline

Klugmann M, Schwab MH, Pühlhofer A, Schneider A, Zimmermann F, Griffiths IR, Nave KA (1997) Assembly of CNS myelin in the absence of proteolipid protein. Neuron 18:59-70. CrossRef Medline

Lebrun-Julien F, Bachmann L, Norrmén C, Trötzmüller M, Köfeler H, Rüegg MA, Hall MN, Suter U (2014) Balanced mTORC1 activity in oligodendrocytes is required for accurate CNS myelination. J Neurosci 34:84328448. CrossRef Medline

Lin J, Wu PH, Tarr PT, Lindenberg KS, St-Pierre J, Zhang CY, Mootha VK, Jäger S, Vianna CR, Reznick RM, Cui L, Manieri M, Donovan MX, Wu Z, Cooper MP, Fan MC, Rohas LM, Zavacki AM, Cinti S, Shulman GI, et al. (2004) Defects in adaptive energy metabolism with CNS-linked hyperactivity in PGC-1alpha null mice. Cell 119:121-135. CrossRef Medline

Liu J, Magri L, Zhang F, Marsh NO, Albrecht S, Huynh JL, Kaur J, Kuhlmann 
T, Zhang W, Slesinger PA, Casaccia P (2015) Chromatin landscape defined by repressive histone methylation during oligodendrocyte differentiation. J Neurosci 35:352-365. CrossRef Medline

Livak KJ, Schmittgen TD (2001) Analysis of relative gene expression data using real-time quantitative PCR and the $2-\delta \delta C_{\mathrm{T}}$ method. Methods 25: 402-408. CrossRef Medline

Malhas AN, Lee CF, Vaux DJ (2009) Lamin B1 controls oxidative stress responses via Oct-1. J Cell Biol 184:45-55. CrossRef Medline

Melberg A, Hallberg L, Kalimo H, Raininko R (2006) MR characteristics and neuropathology in adult-onset autosomal dominant leukodystrophy with autonomic symptoms. AJNR Am J Neuroradiol 27:904-911. Medline

Nakahara J, Kanekura K, Nawa M, Aiso S, Suzuki N (2009) Abnormal expression of TIP30 and arrested nucleocytoplasmic transport within oligodendrocyte precursor cells in multiple sclerosis. J Clin Invest 119:169181. CrossRef Medline

Norrmén C, Figlia G, Lebrun-Julien F, Pereira JA, Trötzmüller M, Köfeler HC, Rantanen V, Wessig C, van Deijk AL, Smit AB, Verheijen MH, Rüegg MA, Hall MN, Suter U (2014) mTORC1 controls PNS myelination along the mTORC1-RXRgamma-SREBP-lipid biosynthesis axis in Schwann cells. Cell Rep 9:646-660. CrossRef Medline

Padiath QS, Fu YH (2010) Autosomal dominant leukodystrophy caused by lamin B1 duplications a clinical and molecular case study of altered nuclear function and disease. Methods Cell Biol 98:337-357. CrossRef Medline

Padiath QS, Saigoh K, Schiffmann R, Asahara H, Yamada T, Koeppen A, Hogan K, Ptácek LJ, Fu YH (2006) Lamin B1 duplications cause autosomal dominant leukodystrophy. Nat Genet 38:1114-1123. CrossRef Medline

Pruitt KD, Tatusova T, Brown GR, Maglott DR (2012) NCBI reference sequences (RefSeq): current status, new features and genome annotation policy. Nucleic Acids Res 40:D130-135. CrossRef Medline

Saher G, Brügger B, Lappe-Siefke C, Möbius W, Tozawa R, Wehr MC, Wieland F, Ishibashi S, Nave KA (2005) High cholesterol level is essential for myelin membrane growth. Nat Neurosci 8:468-475. CrossRef Medline

Schwankhaus JD, Katz DA, Eldridge R, Schlesinger S, McFarland H (1994) Clinical and pathological features of an autosomal dominant, adult-onset leukodystrophy simulating chronic progressive multiple sclerosis. Arch Neurol 51:757-766. CrossRef Medline
Shao W, Espenshade PJ (2012) Expanding roles for SREBP in metabolism. Cell Metab 16:414-419. CrossRef Medline

Shen S, Sandoval J, Swiss VA, Li J, Dupree J, Franklin RJ, Casaccia-Bonnefil P (2008) Age-dependent epigenetic control of differentiation inhibitors is critical for remyelination efficiency. Nat Neurosci 11:1024-1034. CrossRef Medline

Shimi T, Pfleghaar K, Kojima S, Pack CG, Solovei I, Goldman AE, Adam SA, Shumaker DK, Kinjo M, Cremer T, Goldman RD (2008) The A- and B-type nuclear lamin networks: microdomains involved in chromatin organization and transcription. Genes Dev 22:3409-3421. CrossRef Medline

Shimi T, Butin-Israeli V, Adam SA, Hamanaka RB, Goldman AE, Lucas CA, Shumaker DK, Kosak ST, Chandel NS, Goldman RD (2011) The role of nuclear lamin B1 in cell proliferation and senescence. Genes Dev 25: 2579-2593. CrossRef Medline

Shroff SM, Pomicter AD, Chow WN, Fox MA, Colello RJ, Henderson SC, Dupree JL (2009) Adult CST-null mice maintain an increased number of oligodendrocytes. J Neurosci Res 87:3403-3414. CrossRef Medline

Stancheva I, Schirmer EC (2014) Nuclear envelope: connecting structural genome organization to regulation of gene expression. Adv Exp Med Biol 773:209-244. CrossRef Medline

Sundblom J, Melberg A, Kalimo H, Smits A, Raininko R (2009) MR imaging characteristics and neuropathology of the spinal cord in adult-onset autosomal dominant leukodystrophy with autonomic symptoms. AJNR Am J Neuroradiol 30:328-335. CrossRef Medline

Tyurina YY, Kisin ER, Murray A, Tyurin VA, Kapralova VI, Sparvero LJ, Amoscato AA, Samhan-Arias AK, Swedin L, Lahesmaa R, Fadeel B, Shvedova AA, Kagan VE (2011) Global phospholipidomics analysis reveals selective pulmonary peroxidation profiles upon inhalation of singlewalled carbon nanotubes. ACS Nano 5:7342-7353. CrossRef Medline

Werner HB, Krämer-Albers EM, Strenzke N, Saher G, Tenzer S, OhnoIwashita Y, De Monasterio-Schrader P, Möbius W, Moser T, Griffiths IR, Nave KA (2013) A critical role for the cholesterol-associated proteolipids PLP and M6B in myelination of the central nervous system. Glia 61:567-586. CrossRef Medline

Yamashita T, Wu YP, Sandhoff R, Werth N, Mizukami H, Ellis JM, Dupree JL, Geyer R, Sandhoff K, Proia RL (2005) Interruption of ganglioside synthesis produces central nervous system degeneration and altered axonglial interactions. Proc Natl Acad Sci U S A 102:2725-2730. CrossRef Medline 